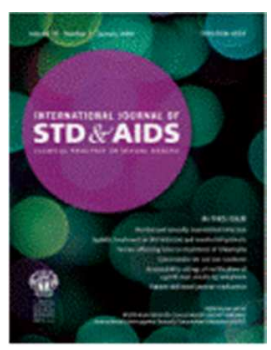

\title{
UK Guideline for the use of HIV Post-Exposure Prophylaxis Following Sexual Exposure (PEPSE), 2015
}

\begin{tabular}{|c|c|}
\hline Journal: & International Journal of STD \& AIDS \\
\hline Manuscript ID & Draft \\
\hline Manuscript Type: & Guidelines \\
\hline Date Submitted by the Author: & $\mathrm{n} / \mathrm{a}$ \\
\hline Complete List of Authors: & $\begin{array}{l}\text { Cresswell, Fiona; Brighton and Sussex University Hospital, Specialist } \\
\text { Registrar in HIV and Sexual health } \\
\text { Waters, Laura; Mortimer Market Centre, Consultant HIV and Sexual } \\
\text { Health; BASHH HIV Special Interest Group } \\
\text { Briggs, Eleanor; National AIDS Trust } \\
\text { Fox, Julie; Guy \'s and St Thomas\' Hospital; King\'s College London, } \\
\text { Honorary Senior Lecturer } \\
\text { Harbottle, Justin; Terrence Higgins Trust } \\
\text { Hawkins, David; Chelsea and Westminster Hospital, Consultant HIV and } \\
\text { Sexual Health } \\
\text { Murchie, Martin; Society of Sexual Health Advisers; NHS Greater Glasgow } \\
\text { and Clyde, Senior Sexual Health Adviser } \\
\text { Radcliffe, Keith; Whittall Street Clinic, Consultant Genitourinary Medicine; } \\
\text { Chair of BASHH Clinical Effectiveness Group } \\
\text { Rafferty, Paul; HIV Pharmacy Association; Belfast Health and Social Care } \\
\text { Trust } \\
\text { Rodger, Alison; University College London, Reader/Honorary Consultant in } \\
\text { Infectious Diseases and HIV } \\
\text { Fisher, Martin; Brighton and Sussex University Hospitals, Consultant HIV } \\
\text { and Sexual Health; Brighton and Sussex Medical School, Professor of HIV } \\
\text { Medicine }\end{array}$ \\
\hline Keyword: & $\begin{array}{l}\text { HIV (Human immunodeficiency virus) < Viral disease, Prevention < Other, } \\
\text { HAART (Highly Active Antiretroviral Therapy) < Other, Sexual intercourse } \\
<\text { Other, Sexual behaviour < Other }\end{array}$ \\
\hline \multicolumn{2}{|c|}{ Note: The following files were submitted by the author for peer review, but marked to be sent in Off-Line. } \\
\hline $\begin{array}{l}\text { Manuscript v3 } \\
\text { Appendix C } \\
\text { Appendix B }\end{array}$ & \\
\hline
\end{tabular}


Appendix A

Box 2

Box 1

Table 7

Table 6

Table 5

Table 4

Table 3

Table 2

Table 1

\section{SCHOLARONE \\ Manuscripts}




\section{Title:}

\section{UK Guideline for the use of HIV Post-Exposure Prophylaxis Following Sexual Exposure (PEPSE), 2015}

\section{Authors:}

Fiona Cresswell ${ }^{1}$, Laura Waters ${ }^{2}$, Eleanor Briggs ${ }^{3}$, Julie Fox ${ }^{4}$, Justin

Harbottle $^{5}$, David Hawkins ${ }^{6}$, Martin Murchie ${ }^{7}$, Keith Radcliffe ${ }^{8}$, Paul

Rafferty $^{9}$, Alison Rodger ${ }^{10}$, Martin Fisher ${ }^{1,11}$

${ }^{1}$ Specialist Registrar HIV and Sexual Health, Lawson Unit, Brighton and Sussex University Hospital

${ }^{2}$ BASHH HIV Special Interest Group, Consultant HIV and Sexual Health, Mortimer Market Centre, London

${ }^{3}$ National AIDS Trust

${ }^{4}$ Consultant HIV Medicine and Clinical Trials, Guy's and St Thomas' Hospital, London.

Honorary Senior Lecturer Kings College London

${ }^{5}$ Terrence Higgins Trust

${ }^{6}$ Consultant HIV and Sexual Health, Chelsea and Westminster Hospital, London

${ }^{7}$ Society of Sexual Health Advisers

${ }^{8}$ Chair BASHH Clinical Effectiveness Group, Consultant HIV and Sexual Health Whittall Street Clinic, Birmingham

${ }^{9}$ HIV Pharmacy Association

${ }^{10}$ Reader/Honorary Consultant Infectious Diseases \& HIV, University College London

${ }^{11}$ Chair of writing group, late Professor of HIV medicine at Brighton and Sussex University Hospital

Corresponding author:

Fiona Cresswell, Lawson Unit, Royal Sussex County Hospital, Brighton, BN2 5BE fiona.cresswell@bsuh.nhs.uk 


\begin{abstract}
:
We present the updated British Association for Sexual Health and HIV guidelines for HIV postexposure prophylaxis following sexual exposure (PEPSE). This document includes a review of the current data to support the use of PEPSE, considers how to calculate the risks of infection after a potential exposure, and provides recommendations on when PEPSE should and should not be considered. We also review which medications to use for PEPSE, provide a checklist for initial assessment and make recommendations for monitoring individuals receiving PEPSE. Special scenarios, cost-effectiveness of PEPSE and issues relating to service provision are also discussed. Throughout the document, the place of PEPSE within the broader context of other HIV prevention strategies is considered.
\end{abstract}

\title{
Keywords:
}

Post-exposure prophylaxis (PEP), sexual exposure, HIV prevention, BASHH guidelines, antiretroviral therapy 


\section{New in the 2015 guidelines:}

1. PEPSE is not routinely recommended after any type of sex with HIV-positive source on antiretroviral therapy (ART) with a confirmed and sustained ( $>6$ months) undetectable plasma HIV viral load $(<200 \mathrm{c} / \mathrm{ml})$.

2. Initiation of PEPSE is recommended as soon as possible after exposure, preferably within 24 hours of exposure but can be offered up to 72 hours.

3. The first-line regimen is Truvada and raltegravir.

4. Routine blood test monitoring is not recommended for raltegravir-based PEP with normal baseline blood tests, unless clinically indicated.

5. Follow-up HIV testing is recommended 8-12 weeks after exposure.

6. It is acceptable to provide the full 28-day course of PEPSE on first visit to a specialist clinic provided the recipient has met with a Sexual Health Adviser, source testing is not possible and there are no clinical or adherence concerns.

7. PEPSE is an emergency method of HIV prevention and should not be considered or encouraged as a method of first resort. Other evidence-based HIV prevention methods should be discussed.

8. If further risk occurs during the last two days of the PEPSE course, then PEPSE should be continued for 48 hours after the last high-risk sexual exposure.

9. In the event of a new HIV diagnosis after initiation of PEP, PEP should be continued pending discussion with an HIV specialist. Long-term ART may be beneficial in the setting of primary HIV infection.

10. If the recipient has missed more than 48 hours of PEPSE then the course should be discontinued. 


\section{Summary of recommendations:}

\section{When to use PEPSE?}

We recommend the use of PEPSE where there is a significant risk of HIV transmission (risk $>1 / 1000$ ), see Table 3 (1C).

If the source is of unknown status:

$>$ We suggest proactive attempts are made to establish the HIV status of the source (2C).

Source individual known to be HIV-positive:

$>$ Attempts should be made at the earliest opportunity to determine the HIV viral load, resistance profile and treatment history (1D).

$>$ PEPSE is no longer recommended if the source is on antiretroviral therapy (ART) with a confirmed and sustained (>6 months) undetectable plasma HIV viral load (<200c/ml) (1B). However, if there are any doubts about the HIV viral load history or the source's adherence to ART then PEP should be given following unprotected receptive anal intercourse.

$>$ Individuals should be encouraged to attend for formal PEP assessment and verification of source's HIV details even when they believe the source has an undetectable HIV viral load (GPP).

$>$ If drug resistance is suspected in the source the regimen should be tailored accordingly following discussion with an HIV physician (1D).

\section{What to use for PEPSE?}

We recommend the use of Truvada and raltegravir as the regimen of choice for PEPSE (1B). See Table 4 for alternatives regimens and Appendix A for interactions.

We recommend that an accurate medication history should be taken, including the use of over the counter medication, vitamins/minerals, herbal remedies and recreational drugs before PEPSE is prescribed (1D).

\section{How to use PEPSE?}

We recommend PEPSE should be initiated as soon as possible after exposure, preferably within 24 hours, but can be considered up to 72 hours (1D).

We do not recommend giving PEPSE beyond 72 hours (1D).

We recommend that the duration of PEPSE should be 28 days (1D).

PEPSE should not be considered or encouraged as a first-line method of HIV prevention. Other more evidence-based methods should be discussed (1C). 
We recommended that all individuals attending for PEP be strongly encouraged to meet with an appropriate health care professional competent in sexual health advising to discuss risk reduction. Provision of PEPSE should be fully integrated into counselling around safer sex strategies (1C).

We suggest individuals seeking PEPSE should be encouraged to attend for future regular sexual health check-ups $(2 \mathrm{C})$.

We recommend that an accurate medication history should be obtained, including use of over the counter medications, vitamins/minerals, herbal remedies and recreational drugs before PEPSE is prescribed (1D).

We suggest routine blood test monitoring after initiation of raltegravir-based PEPSE is not necessary unless clinically indicated or if baseline blood tests are abnormal $(2 \mathrm{C})$.

We suggest performing an STI screen at baseline as indicated, as well as at 2 weeks post-exposure $(2 \mathrm{C})$.

We recommend follow-up HIV testing at 8-12 weeks after exposure (1C).

We recommend using a $4^{\text {th }}$ generation laboratory venous blood HIV test at baseline and for followup testing (1D).

We suggest offering an ultra-rapid course of Hepatitis B vaccination if clinically indicated and the individual has no immunity at baseline (GPP).

We recommend pregnancy testing in women considering PEPSE (1D). We suggest pregnancy should not alter the decision to start PEPSE (2D). Women must be counselled that antiretroviral agents used for PEPSE are unlicensed in pregnancy and risks / benefits must be carefully discussed (1D).

In the event of a further high-risk sexual exposure in the last two days of the PEPSE course the PEP should be continued for 48 hours after the last high-risk exposure (2B).

Individuals experiencing a skin rash or flu-like illness during or after taking PEPSE should be advised to attend for urgent review to exclude an HIV seroconversion illness (2D).

If the HIV test is positive after PEPSE has already been initiated we recommend continuing PEPSE pending review by an HIV specialist (GPP).

For PEPSE to be maximally effective 24-hour availability is recommended (1C). This should include out of hours expert advice if required (1D).

Information about PEPSE should be included when counselling individuals at risk of acquiring HIV infection as well as those already diagnosed with HIV infection (2D). 


\section{Contents:}

1. Objectives

2. Methods

2.1 Search strategy

2.2 Stakeholder involvement, piloting and feedback

3. Background

4. Risk of HIV transmission

5. Data supporting the use of PEP against HIV

5.1 Animal studies

5.2 Human studies

6. Factors influencing the efficacy of PEP

7. Possible risks of PEP

7.1 Safety

7.2 Behavioral implications

7.3 Acute anxiety

8. Comparison with other HIV prevention strategies

9. Recommendations for prescribing PEPSE

9.1 Source individual of unknown HIV status

9.2 Source individual known to be HIV-positive

9.3 Needle-stick injury in the community

9.4 Human bites

9.5 Sexual assault

9.6 Commercial sex workers

10. Assessment and initial management

11. Timing of PEP

12. Duration of PEP

13. Which medication regimen to use for PEP

13.1 NRTI

13.2 INI

13.3 NNRTI

$13.4 \mathrm{PI}$

13.5 CCR5-receptor antagonists

13.6 Side effects

13.7 Interactions

14. Monitoring and Follow-up

15. Special scenarios

15.1 Pregnancy

15.2 Skin rash or flu-like symptoms during or after PEP

15.3 Discontinuation or missed doses of PEP

15.4 Further high-risk sexual exposures whilst on PEP

15.5 Management of individuals who repeatedly present for PEPSE or with ongoing highrisk behavior

15.6 Management of those with a positive HIV test at baseline or after initiating PEP

16. PEP service provision

17. Awareness of PEPSE

18. Cost-effectiveness

19. Surveillance on use of PEPSE 
20. Qualifying statement

21. Applicability

22. Auditable outcome measures

23. Acknowledgements

24. Conflicts of Interest

Appendix A. Potential of Drug Interactions

Appendix B. PEPSE assessment checklist

Appendix C. Levels and GRADE of evidence

References 


\section{Objectives:}

We aim to provide evidence-based recommendations for the most appropriate use of HIV postexposure prophylaxis following sexual exposure (PEPSE). The aim of PEPSE is to prevent HIV transmission. Risk of transmission, timing of PEP, preferred regimen, drug-drug interactions, followup, risk reduction and special scenarios are discussed. Consideration is given to the role of PEPSE within the broader context of HIV prevention and sexual health.

The guideline is intended to be complementary to existing Department of Health and Expert Advisory Group on AIDS (EAGA) guidance on PEP (1). It is aimed primarily at clinicians and policymakers in sexual health, sexual assault referral centres (SARCs), and primary and emergency care providers within the UK who should consider the development of appropriate local pathways. It is likely that this guideline will also be used for information provision by voluntary sector agencies to provide information for individuals.

The recommendations are aimed primarily at individuals aged 16 or older and may not be appropriate for use in all situations, including occupational exposures. Decisions to follow these recommendations must be based on the professional judgment of the clinician and consideration of individual patient circumstances and available resources.

\section{Methods:}

The multidisciplinary guideline-working group developed the guidelines based on processes outlined in the BASHH Framework for Guideline Development (2). The guideline is based on a comprehensive literature review on PEPSE and HIV transmission. All members underwent GRADE training. The recommendations are the result of a series of face-to-face and virtual meetings of the Writing Committee and will incorporate input from the public consultation process.

PICO questions were set as:

POPULATIONS: sexual, non-occupational, bite exposure to HIV

INTERVENTION: post-exposure prophylaxis, PEP, PEPSE, antiretroviral therapy

COMPARISON: no intervention, ART treatment as prevention (TasP), condoms, pre-exposure prophylaxis (PrEP)

OUTCOME: HIV infection, seroconversion, toxicity, completion, sexual behavior, cost-effectiveness

\subsection{Search strategy:}


Current British Association for Sexual Health and HIV (3), USA Centers for Disease Control and Prevention (4), World Health Organisation (5) and Australian Society of HIV Medicine guidelines were reviewed (6).

Medline, Embase, Cochrane Library were searched from January 1990 to November 2014 for all articles relating to HIV post-exposure prophylaxis (985 abstracts reviewed). Search terms were HIV AND post-exposure prophylaxis, PEP, PEPSE, non-occupational, sexual, antiretroviral, chemoprophylaxis. A second search from 2008 to November 2014 was conducted for HIV transmission (2493 abstracts reviewed). Search terms were HIV AND transmission AND risk / risk reduction. Conference abstracts from Conference on Retroviruses and Opportunistic Infection, World AIDS, Interscience Conference on Antimicrobial Agents and Chemotherapy (ICAAC), HIV Drug Therapy from January 2012 to November 2014 were reviewed.

Restrictions: English language papers.

\subsection{Stakeholder involvement, piloting and feedback:}

The guideline-working group included representatives from the British Association for Sexual Health and HIV (BASHH), British HIV Association (BHIVA), EAGA, Society of Sexual Health Advisers (SSHA), HIV Pharmacy Association (HIVPA), the Terrence Higgins Trust (THT) and the National AIDS Trust (NAT). Patients' perspectives were considered by involvement of THT and NAT, reviewing the literature for information from patient surveys and the public consultation process.

\section{Background:}

Pathogenesis studies indicate that there may be a window of opportunity to avert HIV infection by inhibiting viral replication following an exposure. Once HIV crosses a mucosal barrier it may take up to 48-72 hours before HIV can be detected within regional lymph nodes and up to five days before HIV can be detected in blood $(7,8)$. Initiation of antiretroviral therapy (ART) has been shown to reduce dissemination and replication of virus in all tissues if initiated early after inoculation in an animal model (9).

\section{Risk of HIV transmission:}

The probability of HIV transmission depends upon the exposure characteristics, the infectivity of the source and host susceptibility. Where individuals have multiple exposures within 72 hours a cumulative risk should be considered. 
Table 1 shows the estimated HIV prevalence (including both diagnosed and undiagnosed infection) in adults aged over 15-59 years in the UK in 2014. HIV prevalence in other countries can be found in the UNAIDS 2014 Gap report:

http://www.unaids.org/en/resources/campaigns/2014/2014gapreport/gapreport

The risk of HIV transmission per exposure from a known HIV-positive individual not on ART is summarized in table 2. These figures are estimates that have been deduced from cohort and modeling studies.

The risk of an individual acquiring HIV following an exposure can be calculated by multiplying the risk that the source is HIV-positive (Table 1) and the risk per exposure (Table 2):

\section{Risk of HIV transmission $=$ risk that source is HIV positive $\mathrm{x}$ risk per exposure}

For example, if a man presents for PEPSE following unprotected receptive anal intercourse with ejaculation with male partner of unknown HIV status in London:

Risk of HIV transmission $=12.5 / 100 \times 1 / 65=12.5 / 6500=1 / 520$

However, certain factors may increase the risk of HIV transmission and must be considered and discussed in a PEP consultation, see box 1 :

\section{Data supporting the use of PEP against HIV:}

\subsection{Animal studies}

Animal studies suggest that PEP can be potentially effective and that time to initiation and duration are important. Animal studies are not standardised and use different retroviruses, size of inocula and modes of administration; this may, at least in part, explain their differing results.

Two studies demonstrated effectiveness of subcutaneous PMPA (tenofovir) in macaque models following intravenous SIV (46) or intravaginal HIV-2 inoculation (47); efficacy was highest if PEP was administered within 24-36 hours and continued for 28 days. In another macaque study, oral zidovudine, lamivudine and indinavir offered no protection following intravenous exposure (48), though this may have been due to inoculation mode and/or size. The same group demonstrated that higher dose oral PEP was effective following intravaginal exposure highlighting the importance of achieving adequate drug concentrations (49).

More recent animal studies have demonstrated effectiveness of intermittent pre-exposure 
prophylaxis (PrEP) and PEP using oral Truvada (tenofovir and emtricitabine) in macaques following rectal inoculation. The highest level of protection was achieved with a first dose 22 hours to seven days prior to the exposure and a second dose two hours after the exposure (50).

\subsection{Human studies}

Prospective randomized controlled trials (RCTs) to determine the efficacy of PEPSE have not been performed and are not feasible due to the ethics of withholding a potentially efficacious treatment and the difficulty in recruiting a sufficient sample size.

\section{a) Occupational exposure to HIV}

A retrospective case-controlled study among health-care workers occupationally exposed to HIV infection demonstrated that a 28-day course of zidovudine was protective, odds ratio (OR) 0.19 (95\% confidence interval (Cl) $0.06-0.52 \%$ ) (29). However there are also instances where PEP has failed to prevent HIV infection following occupational exposure (51).

\section{b) Vertical transmission}

In a subset of women in the AIDS Clinical Trials Group (ACTG) 076 study who did not receive zidovudine prior to delivery but where the neonate was given a six-week course of zidovudine, initiated within 48 hours of delivery, a protective effect was observed $(52,53)$.

\section{C) Sexual exposure to HIV}

No prospective RCTs to determine the efficacy of PEPSE were identified. Two observational PEPSE studies undertaken in Brazil, one among MSM and another in women following sexual assault, demonstrated that fewer HIV seroconversions in individuals receiving PEPSE compared with those who did not. However, neither study was powered to detect a difference in HIV incidence (54).

\section{Factors influencing the efficacy of PEP:}

PEP is not considered $100 \%$ effective, as there have been cases of HIV acquisition whilst on PEP. These may be related to:

- Delayed initiation $(29,46)$

- Transmission of resistant virus

- Variable genital tract drug penetration

- Poor/non-adherence

- Further high risk sexual exposures 
Baseline HIV resistance recorded on the UK HIV Drug Resistance Database is declining amongst MSM in the UK (7.2\%, in 2013) but is stable amongst heterosexuals (6.0\% in 2013). No baseline integrase resistance has been detected in the national database but the data is limited (120 tests 2010-2012). Integrase-experienced patients demonstrate stable levels of resistance at $15 \%$ of those tested, though rates may be higher in other countries (55). If drug resistance is suspected in the source the regimen should be tailored accordingly following discussion with an HIV physician (1C).

Poor adherence was a risk for subsequent seroconversion in a retrospective analysis of PEPSE failures (56). A recent case-series of 19 HIV diagnoses after PEPSE initiation found that one was a chemoprophylactic failure related to suboptimal dosing of Kaletra in the first week of treatment; the other 18 had primary HIV at baseline (57). Worryingly PEP completion rates to 28-days have been historically poor in the UK (range 42-82\%) (58-67).

\section{Possible risks of PEPSE:}

\subsection{Safety}

The possibility of side effects and both short and potential long-term toxicities must be balanced with the potential benefit of PEP. This has been considered when determining risk thresholds for recommending PEPSE.

\subsection{Behavioural implications:}

Historically there were concerns that PEPSE availability would reduce commitment to other prevention strategies. However several studies have demonstrated a reduction in self-reported risk behaviour: a Brazilian MSM cohort (54) and two San Francisco clinics providing PEPSE to MSM (68). PEP awareness had no effect on condom use by serodiscordant couples in a cross-sectional survey (69).

Conversely, some authors have argued that health-related interventions such as PEPSE may actually provide benefit by capitialising on 'close calls' to motivate and sustain risk reduction in individuals who have engaged in risk behavior (70).

\subsection{Acute anxiety}

The decision to administer PEPSE should be based on the risk of HIV acquisition and not to manage a state of acute anxiety following a sexual exposure. Referral for psychological support for individuals reporting anxiety related to the risk of HIV transmission may be beneficial (2D). 


\title{
8. Comparison with other HIV prevention strategies:
}

\author{
PEPSE should not be considered or encouraged as a first line method of HIV \\ prevention (1C)
}

The Writing Committee believes it is crucial to consider PEPSE as only one strategy for preventing HIV infection and must be considered within the broader context of HIV prevention. Other methods of HIV prevention have a more robust evidence base and as such PEPSE should not be considered or encouraged as a first line method of HIV prevention (1C). Alternative methods of HIV prevention and their respective effectiveness are summarized in the BHIVA/BASHH position statement on HIV Pre-exposure Prophylaxis and should be used to aid discussion of the options available to service users (71): http://www.bhiva.org/documents/Publications/PrEP2012.pdf. Condoms are highly protective, although use is inconsistent $(12,72)$. Data in support of treatment of HIV-positive partners as a prevention strategy is strong $(13,14)$.

The Writing Committee anticipates that, pending results of discussions at the time of guideline development, the repertoire of prevention tools will expand to include pre-exposure prophylaxis (PrEP); individuals presenting for PEPSE may be candidates for PrEP when it becomes available.

\section{Recommendations for prescribing PEPSE:}

\section{We recommend the use of PEPSE where there is a significant risk of HIV transmission (1C)}

A risk-benefit analysis should be undertaken for every individual presenting following an exposure and the decision to initiate PEPSE made on a case-by-case basis. This should consider both the risk of the source being HIV-positive (Table 1), the risk of transmission according to exposure (Table 2) and as well as the viral load in the source, if known. The recommendations are summarised in Table 3. Awareness of the local HIV seroprevalence in the potential source should be factored into local protocols.

The Writing Committee suggests using the following threshold to determine if PEPSE is indicated:

○ Transmission risk is greater than 1 in 1000 - PEPSE is recommended (2D).

$\circ$ Transmission risk is between 1 in 1000 and 1 in 10,000 - PEPSE may be considered 
(2D). The Writing Committee feels that when the exposure is classified as 'consider', PEPSE should only be prescribed if there are additional factors that may increase the likelihood of transmission (see Box 1).

- Transmission risk is less than 1 in 10,000 PEPSE is not recommended (2D).

\subsection{Source individual is of unknown HIV status}

\section{We suggest proactive attempts are made to establish the HIV status of the source (2C)}

Proactive attempts should be made to establish the HIV status of the source as early as possible (2C). It has been shown that in presentations following sexual intercourse with a source of unknown HIV status it was possible to contact and test the source in $43.4 \%$ of cases and avoid/discontinue PEPSE in 40.7\%; this resulted in a $31 \%$ reduction in cost. Importantly, this strategy avoids unnecessary side effects and toxicity for the individual and facilitates HIV-testing of a high-risk group $(73,74)$. It is therefore recommended that appropriate partner notification is undertaken and the source tested for HIV as soon as possible; this should not delay PEPSE initiation.

If the source is from a risk-group or country of high HIV prevalence (prevalence $>1 \%$ ) then PEPSE is routinely recommended following receptive anal sex, see Table 3.

\subsection{Source individual known to be HIV-positive:}

We suggest attempts should be made at the earliest opportunity to determine the plasma HIV viral load, resistance profile and treatment history of the source (GPP)

If source individual is known to be HIV-positive attempts should be made at the earliest opportunity to determine the HIV viral load, resistance profile and treatment history.

Observational studies have long demonstrated a protective effect of viral suppression on risk of transmission (75-77). Then followed the HPTN 052 study, an RCT primarily in heterosexual serodifferent couples, which demonstrated a 96\% reduction in HIV transmission risk with suppressive ART (78). Most recently, the PARTNER Study demonstrated no linked transmissions from people with plasma HIV-1 RNA load $<200$ copies/mL despite a large number of condomless sex acts with serodifferent partners ( $>28,000$ acts in heterosexuals and $>16,000$ acts in MSM) (79). 
In light of this the recommendation for receptive anal sex with a HIV-positive partner with an undetectable plasma HIV VL (confirmed VL<200 copies/ml sustained for $>6$ months and high adherence to ART) has been changed from 'recommended' to 'not-recommended', see Table 3 (1B).

PEPSE is no longer recommended if the source is on ART with a confirmed and sustained (>6 months) undetectable plasma HIV viral load (<200copies $/ \mathrm{ml}$ ) (1B)

The dates and results of the source's last viral load tests should be confirmed with their clinic for a minimum of the last 6 months and recorded in the PEP assessment. If there is any doubt about the source's viral load or adherence to ART then PEPSE should be given as a precaution following unprotected anal intercourse.

Individuals should be encouraged to attend for formal PEP assessment and verification of source's HIV details even when they believe the source has an undetectable HIV viral load (GPP)

PEPSE is 'not-recommended' following fellatio with ejaculation as we believe the risk is $<1 / 10,000$ (2C). A cohort study demonstrated that after an estimated total of over 19,000 unprotected orogenital exposures with an HIV-positive partner no HIV seroconversions occurred (25). Case reports of oral transmission exist and modeling studies have estimated a risk of 4/10,000 (12). In extreme circumstances such as primary HIV infection and oropharyngeal trauma / ulceration PEP can be considered but in general PEP is not recommended. PEPSE is also not recommended following semen splash in the eye as there have been no documented HIV transmissions via this route (GPP). Following insertive vaginal intercourse with an HIV-positive partner not on ART, PEPSE should be 'considered' rather than routinely 'recommended' as the risk is $<1 / 1219(14,15$, 19) (2C). Again, presence of additional factors in Box 1 should be reviewed and clinician discretion applied.

\subsection{Needlestick injury in the community}

In general, PEP is not recommended following a community needlestick exposure as it is usually not possible to determine: (i) whether the needle has been used and for what purpose; (ii) the HIV status of the source and; (iii) the interval between the needle use and the exposure (2D). Once blood has dried, HIV becomes non-viable within a couple of hours. In studies where only small amounts of blood are in the syringe viable HIV cannot be detected after 24 hours (80). 


\subsection{Human bites}

Requests for PEP following human bites have been reported. In general PEP is not recommended following a bite as, although the risk of transmission is unknown, it is likely to be extremely small (2D). In the few reported cases of HIV-transmission following a bite the person inflicting the bite had advanced HIV with a high plasma viral load, there was blood in the oropharynx from trauma or deep wounds were caused by the bite $(31,32)$. In extreme circumstances PEP could be considered after discussion with a specialist. Further guidance regarding the management of human bites is available at: $\underline{\text { http://cks.nice.org.uk/bites-human-and-animal\#!scenario:1 }}$

\subsection{Sexual assault}

It is believed that transmission of HIV is likely to be increased as a result of any trauma following aggravated sexual intercourse (anal or vaginal). Clinicians may therefore consider recommending PEPSE more readily in such situations, particularly if the assailant is from a high prevalence group (81). It is likely that the uptake will be lower in UK settings if the assailant is from a low prevalence group after the balance of risks and benefits are discussed with the patient (2D).

\subsection{Commercial sex workers}

Historically in Western Europe, HIV prevalence among female sex workers has remained low $<1 \%$. Prevalence of HIV is also low in Central Europe (1\% - 2\%) but is higher in Eastern Europe ranging between $2.5 \%$ and $8 \%$ (82). HIV prevalence is greatest in sex workers who inject drugs (82). HIV prevalence among male sex workers, reported from 27 countries, was $14 \%$ (83).

\section{Assessment and initial management:}

We suggest individuals presenting for PEPSE should be encouraged to attend for regular sexual health check-ups and are referred to risk-reduction services if appropriate (2C)

It is essential that an appropriate risk assessment be performed to enable provision of PEPSE according to the recommendations outlined above. A checklist outlining the necessary risk assessment for HIV and hepatitis $\mathrm{B} / \mathrm{C}$ has been created which may be a useful tool in PEP consultations, see Appendix B. At presentation, and prior to administration of PEPSE, the following issues, summarized in Box 2, must be discussed with the individual:

Early assessment in a specialist Sexual Health service, including meeting with a counsellor / sexual health advisor has been shown to improve rates of adherence and follow-up HIV testing $(84,85)$. 
Individuals presenting for PEPSE are at higher risk of future acquisition of HIV (68) and so should be encouraged to attend for future regular sexual health check-ups and considered for referral to risk-reduction services and for HIV Pre-Exposure Prophylaxis when this becomes available (2C).

\section{Timing of PEPSE:}

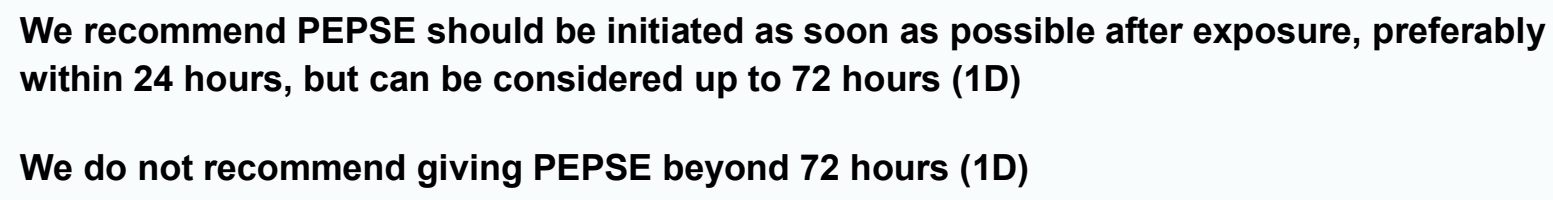

In a recent study in rhesus monkeys ART was initiated on day 3 following an intrarectal inoculum of SIV in rhesus monkeys. This blocked emergence of viral RNA and proviral DNA in peripheral blood, lymph nodes and gastrointestinal tract but on discontinuation of ART after 24 weeks, all animals experienced viral rebound (86). This supports a maximum 72-hour window of opportunity for PEP; every effort should be made to make PEP obtainable as soon as possible after the exposure.

Starter packs are pre-prepared 3-5 day supplies of antiretrovirals; their use enables timely provision of PEP, especially out of hours or from emergency care facilities. This 'starter' PEPSE regimen can be continued or modified at initial review within five days, depending on further information about the source's HIV status, the source's virus and the patient's tolerance of the medication (2D).

\section{Duration of PEPSE:}

\section{We recommend that the duration of PEPSE should be 28 days (1D)}

The optimal duration of PEP is unknown. However, animal studies and case-controlled studies of health-care workers suggests effectiveness of PEP declines if less than 28 days is used (46). If the source tests negative on a 4th generation laboratory assay then PEP can be discontinued.

If it is unlikely the source can be contacted for HIV testing, there are no significant comorbidities, no baseline blood/urine test abnormalities are predicted and Truvada / raltegravir is used then a complete 28 days supply can be prescribed at the first specialist clinic visit (87). In an emergency care setting initiation of PEP with a 5-day starter pack remains preferable so that early contact with Sexual Health services can be made and STI screening, testing of the source and risk reduction can be facilitated. 


\section{Which medication regimen to use for PEPSE:}

\section{We recommend the use of Truvada and raltegravir as the regimen of choice for PEPSE (1B)}

In established HIV infection, combination therapy with at least three medications from two medication classes is recommended for initial therapy. It is thus recommended, when the risk HIV transmission is considered significant, to use a triple agent regimen for PEPSE (1D). Some international guidelines do recommend dual-class regimens in selected situations $(88,89)$.

If there is evidence that the source has a current or past history of treatment failure, the PEPSE regimen should be modified in relation to the drug history and/or resistance testing, if available. Expert advice should be sought (1D).

\subsection{Nucleoside reverse transcriptase inhibitors (NRTI)}

Truvada (a fixed dose combination of tenofovir and emtricitabine) is recommended as the NRTI backbone based on efficacy, tolerability, safety and convenience. Tenofovir and emtricitabine demonstrate good genital tract and rectal tissue penetration in animal models (reaching peak levels within 24 hours of dosing and maintaining high levels for up to seven days) (48) and good male and female genital tract penetration in human studies (90); these characteristics may be advantageous for PrEP and PEP (48). Phase 3 PrEP studies have demonstrated high efficacy rates for tenofovir (TDF) and Truvada in high-risk heterosexuals and MSM (91-94).

Abacavir is not recommended. A hypersensitivity reaction is reported in up to $8 \%$ of patients with established infection. Although the risk has not been assessed in HIV-negative individuals, it is recommended that abacavir be used in exceptional circumstances only.

\subsection{Integrase inhibitors (INI)}

Integrase inhibitors are well-tolerated and have all demonstrated at least non-inferior efficacy against non-nucleoside reverse transcriptase inhibitors (NNRTI) and protease inhibitors (PI) (95-97). Raltegravir (RAL) has been licensed in Europe since 2007. Elvitegravir and dolutegravir are newer agents with less post-marketing experience; both are currently more expensive than raltegravir and elvitegravir has the added complication of requiring co-administration with cobicistat, a pharmacokinetic booster with a similar drug-drug interaction profile as ritonavir. Neither elvitegravir 
nor dolutegravir has been studied for PEP though both have the advantage of once daily dosing. The Writing Committee believes, based on HIV treatment data, that dolutegravir is an acceptable alternative for individuals who cannot take raltegravir.

Observational studies assessing raltegravir-emtricitabine-tenofovir as PEP in MSM conclude that it is well tolerated, results in high levels of adherence and avoids potential drug-drug interactions (98100). In an RCT, a PEP regimen of Truvada plus raltegravir was better tolerated then Truvada plus Kaletra (101).

Many clinics across the UK have already switched to using raltegravir in favour of Kaletra in PEP regimens since an EAGA statement was released in April 2015: https://www.gov.uk/government/publications/eaga-guidance-on-hiv-post-exposure-prophylaxis

\subsection{Non-nucleoside reverse transcriptase inhibitors (NNRTI)}

Nevirapine-based PEP is not recommended; almost $10 \%$ of individuals experience grade 3 or 4 hepatotoxicity (102) and serious liver toxicity (requiring transplant) and death have been reported. Efavirenz is associated with significant central nervous system side effects, which may be deleterious at a time when levels of anxiety are high; there is no data to support its use in PEP. There is currently also no data to support the use of etravirine or rilpivirine for PEP. StevensJohnson syndrome has been reported with etravirine $(103,104)$.

\subsection{Protease Inhibitors (PI)}

Drug interactions are still of great concern for prescribers experienced in the management of HIV and a challenge for those not experienced in the use of antiretrovirals. One study reports high levels of recreational drug use among MSM genitourinary medicine attendees, an additional interaction concern (105).

Kaletra (lopinavir/ritonavir co-formulation) was the previously recommended PI for PEP. Kaletra is associated with hyperlipidaemia and frequently causes gastrointestinal disturbances (106) necessitating the inclusion of anti-diarrhoeal and antiemetic medication in PEP packs. Side-effects are frequently reported and associated with non-adherence / discontinuation (107).

Darunavir/ritonavir and atazanavir/ritonavir have been studied as alternatives to Kaletra and are both once daily formulations; both were comparable to Kaletra in terms of side-effects and discontinuations $(107,108)$. 


\subsection{CCR5-receptor antagonists}

Maraviroc is well-tolerated and reaches very high levels in the genital tract so its utility for PEP is being investigated. One animal study has shown a lack of prophylactic efficacy despite high drug concentrations in rectal tissues (109).

An RCT concluded that a PEP regimen of Truvada plus maraviroc is better tolerated than Truvada plus Kaletra (101). A study of maraviroc-based PEP in the UK came to similar conclusions (110).

\section{6 Side effects}

Where an individual reports significant current or previous intolerance to one or more PEP agents an alternative agent(s) should be considered (2D).

Any antiretroviral medication may have side effects but these are usually mild. When using Truvada and raltegravir we recommend that the routine inclusion of anti-emetics or anti-diarrhoeals is not necessary; in situations where Kaletra is indicated, routine provision of anti-emetics and antidiarrhoeals should be considered - this may not be necessary with other PI and is unnecessary with dolutegravir. Where anti-emetics are provided domperidone should be NOT be used with PI due to a significant drug-drug interaction with ritonavir (111).

Although proximal renal tubular dysfunction and Fanconi's syndrome are well reported in HIVpositive individuals on tenofovir-based ART, these have not been reported in the setting of PEP or PrEP to date (92).

Myopathy and rhabdomyolysis have been reported with raltegravir (112) and caution should be taken in individuals with a history of these conditions or who are using other medicinal products associated with these conditions, for example statins (www.medicines.org.uk/emc/medicine/20484)

\subsection{Interactions}

We recommend that an accurate medication history should be obtained, including the use of over the counter medication, vitamins/minerals, herbal remedies and recreational drugs before PEPSE is prescribed (1D)

Although raltegravir (and dolutegravir) poses a low risk in-terms of drug-drug interactions, the concomitant use of metal cation containing antacids (aluminium / magnesium / calcium antacids) and multivitamins should be avoided if possible. Dose-adjustment is required with concomitant 
rifampicin use. Pls are associated with numerous drug-drug interactions - see Appendix A for details on interactions.

\section{Monitoring and Follow-up:}

We suggest routine blood test monitoring after initiation of raltegravir-based PEPSE is not necessary unless clinically indicated or if baseline blood tests are abnormal (2C)

PrEP studies support the safety of Truvada in HIV uninfected individuals (92). There have been no reports of proximal renal tubular dysfunction in individuals receiving PEP. The randomized control trial of raltegravir versus Kaletra PEP (combined with a Truvada backbone) did not report any liver, renal or haematological abnormalities in the raltegravir arm (101).

Raltegravir is less commonly associated with transaminitis and hepatic adverse events than protease inhibitors (113). The most at risk group of liver dysfunction are those co-infected with Hepatitis C (114).

Full blood count monitoring is no longer deemed relevant as it does not affect the choice of regime and only a single case report of a transient haematological abnormality has been reported on Kaletra-based PEP (115).

Closer monitoring is however recommended if new symptoms develop on PEPSE (e.g. rash, jaundice, muscle pain) or if the recipient is pregnant, there is a risk of drug-drug interaction or if significant comorbidities such as hepatitis or renal dysfunction exist or if significant abnormalities are detected on baseline testing. Creatinine kinase (CK) should be tested if muscle pain develops on PEP, particularly on raltegravir-based PEP.

We suggest performing STI testing (based on clinical situation) at baseline as well as at 2 weeks post exposure (2C)

Observational studies have found $16.5 \%$ of PEP-recipients had an STI at baseline and an additional $4.1 \%$ had an incubating STI diagnosed at 2 weeks (116). As loss to follow-up is common in PEPrecipients we recommend opportunistic testing at baseline.

\section{We recommend follow-up HIV testing at 8-12 weeks post exposure (1C)}


Several national audits report that the attendance for follow-up HIV testing at 12 weeks is poor (30$67 \%$ ) (61-67). Earlier testing at 8-12 weeks post-exposure may improve testing rates. The HIV test must be on a 4 th generation laboratory assay.

We suggest offering an ultra-rapid course of Hepatitis B vaccination if clinically indicated and the individual has no immunity at baseline (GPP)

In those who do not have immunity to Hepatitis B we suggest offering an ultra-rapid course of Hepatitis B vaccination (or Hepatitis B Immunoglobulin if clinically indicated) as per BASHH guidelines (117). Individual clinic policies on screening tests for Hepatitis $C$ vary; where there has been significant risk a Hepatitis $\mathrm{C}$ core-antigen or Hepatitis C RNA will have greater sensitivity at the time of follow-up tests 8-12 weeks post exposure (118).

\section{Special Scenarios:}

\subsection{Pregnancy}

We recommend pregnancy testing in women considering PEPSE (1D)

We suggest pregnancy should not alter the decision to start PEPSE (2D)

Women must be counselled that antiretrovirals used for PEPSE are unlicensed in pregnancy and risks / benefits must be carefully discussed (1D)

Pregnancy is not a contraindication for PEPSE. Indeed if there is a significant risk of infection, and this is not prevented, the high viraemia associated with primary infection would lead to a high likelihood of intrauterine infection. A thorough risk assessment should be undertaken and expert advice should be sought.

The antiretroviral pregnancy registry (http://www.apregistry.com) demonstrates no increase in birth defects in women exposed to tenofoviremtricitibine during pregnancy, including $1^{\text {st }}$ trimester exposures (APR category B).

There are insufficient reports of raltegravir exposure during pregnancy for it to be catergorised in the APR and its use in pregnancy is currently not advised in the SPC (112). Expert opinion from the 
guideline-working group found raltegravir benefits to outweigh the risks. Kaletra is poorly tolerated in pregnancy and is itself not without risk. Use of antiretroviral medication already characterised on the APR may be preferred by clinician or the patient.

\subsection{Skin rash or flu-like symptoms during or after PEPSE}

Individuals experiencing a skin rash or flu-like illness while or after taking PEPSE should be advised to attend for urgent review to exclude an HIV seroconversion (2D).

\subsection{Discontinuation or missed doses of PEPSE}

Individuals missing doses of PEPSE should be counselled according to the number of missed doses and the time elapsed from the last administered dose. Persistence of PEP medications at therapeutic levels will depend on the pharmacokinetic properties of the individual agents used.

The half-life of raltegravir is relatively short ( 9 hours) such that predicted levels of this agent will be sub-therapeutic 18 hours after a missed dose and largely undetectable by 45 hours. Truvada plasma half-life is $12-18$ hours according to the Summary of Product Characteristics (119) but were longer in a recent study: 31 and 37 hours for tenofovir and emtricitabine, respectively (120). Tenofovir and emtricitabine are activated intracellularly and the median intracellular half-lives are approximately 150-160 hours (120,121); and 39 hours (120), respectively. Recommendations on whether and when to discontinue PEP after missed doses is largely empirical, based on biological and pharmacological rationales as well as expert opinion (see Table 6).

If discontinuation of PEP (for less than 48 hours since the last missed dose) is related to intolerance to one or more ART agents, continue PEP with an alternative agent(s) (see Table 4).

\subsection{Further high-risk sexual exposures while on PEPSE}

\section{In the event of a further high-risk sexual exposure on the last two days of the PEPSE course PEP should be continued for 48hours after the last high-risk exposure (2B)}

Tenofovir and emtricitabine have been shown to prevent acquisition of HIV infection when used as PrEP by MSM $(93,94)$. Individuals reporting further high-risk sexual exposures while receiving PEPSE do not need to extend the course of PEP beyond the initial 28 days. However, should this exposure be on the last two days of the course then extending the treatment for 48 hours after the last exposure should be advised, as this appears to have been highly effective in the IPERGAY study with treatment before and after exposure (2B) (94). 


\title{
15.5 Management of individuals who repeatedly present for PEPSE or with ongoing high-risk behaviour.
}

\author{
We recommended that repeat attenders meet with a health Sexual Health Adviser and/or \\ psychologist and provision of PEPSE is fully integrated into counselling around safer sex \\ strategies (1C)
}

There had been little evidence of repeated PEPSE use $(59,68)$ perhaps due to historically poor tolerability of prescribed regimens. However, in the PROUD study some particularly high-risk subpopulations had high repeat PEPSE usage and, despite this, a high incidence of HIV acquisition (likely due to ongoing risk behaviour which may or may not be covered by PEPSE).

Attending for PEP could be an ideal opportunity to refer individuals for PrEP if it becomes routinely available (under consideration by specialist commissioners at the time of guideline preparation) (122). Until then, it is recommended that repeated attenders be considered for repeat courses of PEPSE on each occasion according to their risk of HIV acquisition. Provision of PEPSE should be fully integrated with advice and counselling around safer sex strategies (1C). It is recommended that in light of the NICE (2007) recommendations (https://www.nice.org.uk/guidance/ph3) these repeat attenders are offered one-to-one structured discussions around a model of behaviour change theory which can address factors that can help reduce risk-taking and improve self-efficacy and motivation.

\subsection{Management of those with a positive HIV test at baseline or shortly after initiating PEPSE:}

HIV testing is mandatory prior to, or shortly after, commencing PEPSE (1A) since undiagnosed HIV infection would significantly alter the risk-benefit balance of short-course ART.

Service providers may obtain rapid results through point-of-care tests (POCTs), although caution must be given to the higher possibility of both false-positive results, and, in early infection, falsenegative. If a POCT is reactive, a 4th generation serological test should be sent urgently and expert advice sought prior to initiating PEP.

If the HIV test is positive after PEPSE has already been initiated we recommend continuing PEPSE pending review by an HIV specialist (GPP) 
If the $4^{\text {th }}$-generation HIV test is positive after PEP has already been initiated we recommend continuing PEP pending review by an HIV specialist. Acute HIV diagnosis after PEPSE initiation represents a unique opportunity for very early ART and the potential benefits that entails (123). Furthermore, stopping ART in the context of acute infection may result in significant viral rebound which could increase the risk of onward transmission (124).

\section{PEPSE Service Provision:}

For PEPSE to be maximally effective 24-hour availability is recommended (1C)

For PEPSE to be maximally effective 24-hour access should be available. Local policies and pathways must be established to enable this within a geographical network. Emergency medicine and urgent care providers will therefore be expected to assume significant responsibility for PEPSE provision. Necessary support and training should be provided by local departments with expertise, such as genitourinary (GU) medicine, HIV medicine, infectious diseases or virology/ microbiology departments. The training issues are essentially those outlined comprehensively in the DH/EAGA guidance on HIV PEP $(1,125)$.

Individuals receiving PEPSE from an emergency or urgent care service should be seen as early as possible by a clinic experienced in the management of ART and HIV testing. PEPSE should not be withheld until such expertise is available. In situations where early referral to an experienced team is not feasible, access to advice from an experienced HIV clinician or team is essential. It is recommended that local policies should include 24-hour access to advice from an experienced HIV clinician, particularly for complex cases (1D).

\section{Awareness of PEPSE:}

It is important that individuals at risk of acquiring HIV are aware of PEPSE, such as those in serodifferent couples or MSM. Levels of awareness of PEPSE are low amongst MSM in London (126-128) and in a cohort of MSM in Australia, those who were PEP-aware sought PEPSE only for a minority of high-risk exposures (68). Whether or not an individual seeks PEP may be related to whether the episode was 'unusual' or a 'one off' and influenced by factors such as characteristics of the sexual partner(s), venue and the use of alcohol and/or recreational drugs (129).

Individuals at risk of HIV should be provided with information regarding indications for, and timing of, PEPSE as well as other proven risk-reduction strategies, see Appendix B. Community based 
organisations will have a large part to play in providing this information. Consideration should be given to provision of 24-hour helpline access to enable individuals to establish whether presentation to hospital services for PEPSE is appropriate (2D). SARCs should ensure that clients and police officers are aware of PEP, and the need for a risk assessment of HIV transmission in each case.

In a UK cohort of people living with HIV overall fewer than half were aware of PEPSE (MSM 65.8\% vs. heterosexual $39.1 \%)(127,130)$. PEPSE should be proactively discussed with individuals diagnosed with HIV infection, particularly if in a serodifferent relationship, reporting frequent partner change or condomless sexual intercourse (GPP).

\section{Cost-effectiveness}

There are no conclusive data regarding the cost-effectiveness of PEPSE. It has been argued that the cost of providing PEP may be effectively spent on other prevention initiatives (131). However, while the medication cost of a full 28-day course of PEP (with Truvada and raltegravir) is approximately $£ 800.14$ (BNF price May 2015), the lifetime costs of treatment for an HIV-positive individual are estimated to be approximately $£ 360,000$ (132). A retrospective cost analysis of the San Francisco PEPSE programme showed it to be cost-effective for high-risk exposures and potentially cost-saving after receptive anal intercourse in MSM (133). Subsequent modelling utilising data from several USA cities (134) and Australia (135) suggests similar cost-effectiveness if PEPSE is targeted to high-risk exposures consistent with these guidelines. This is in general accordance with a review by the Health Technology Assessment (136). A 28-day course of PEP could be substantially less expensive with the use of generic medications available now or in the future.

\section{Surveillance on the use of PEPSE:}

Since January 2011 all episodes of PEPSE in England have been reported through the GUMCAD system (https://www.gov.uk/government/statistics/sexually-transmitted-infections-stis-annual-datatables). Reported PEPSE use has risen annually, particularly amongst MSM. Despite this HIV incidence has risen in MSM over the same time period and other evidence-based strategies must be advocated.

\section{Qualifying statement:}

The recommendations in this guideline may not be appropriate for use in all clinical situations. Decisions to follow these recommendations must be based on the professional judgment of the clinician and consideration of individual patient circumstances and wishes. It should be acknowledged that use of any antiretroviral agent in this setting is an unlicensed indication. All 
possible care has been undertaken to ensure the publication of the correct dosage and route of administration. However, it remains the responsibility of the prescribing physician to ensure the accuracy and appropriateness of the medication they prescribe.

\section{Applicability:}

The provision of PEPSE requires consideration of appropriate pathways of care between Sexual health/HIV clinicians and those providing emergency/primary care, including SARCs, in order to ensure PEPSE is administered in a timely and appropriate fashion. This will require local interpretation of this guideline and will most likely involve a degree of organizational change and pro-vision of additional resources.

\section{Auditable outcome measures:}

1. Proportion of PEPSE patients having a baseline HIV test: aim $100 \%$ within 72 hours of presenting for PEPSE

2. Proportion of PEPSE prescriptions that fit within recommended indications: aim $90 \%$

3. Proportion of PEPSE prescriptions administered within 24 hours of risk exposure: aim $90 \%$

4. Proportion of individuals completing 4-week course of PEPSE: aim $75 \%$

5. Proportion of individuals seeking PEPSE undergoing testing for STIs: aim $90 \%$

6. Proportion of individuals completing 8-12 week post-exposure HIV antibody/antigen test: aim $75 \%$.

\section{Acknowledgements:}

The writing group thanks the following for their valuable contribution to the guideline:

Alison Richards, Beverley Gittins, Sheena McCormack, Sarah Fidler, Marta Boffito, Sonia Raffe, Goleh Haidari

\section{Conflicts of Interest:}

MF, EB, FC, DH, MM, KR, AR none declared. JF has received IST research grants from ViiV and Gilead and speaker fees from Janssen. JH has received speaker fees from Gilead. DH has received conference support from Gilead. PR has received conference support from Gilead. LW has received speaker/advisory board fees or conference support from Bristol Myers Squibb, Gilead Sciences, ViiV Healthcare, Merck Sharpe \& Dohme, Janssen Pharmaceuticals and AbbVie. 


\section{REFERENCES:}

1. AIDS EAGo. Change to recommended regimen for post-exposure prophylaxis (PEP) 2015 [8th July 2015]. Available from:

https://www.gov.uk/government/uploads/system/uploads/attachment data/file/351633/Change to $r$ ecommended regimen for PEP starter pack final.pdf.

2. British Association for Sexual Health and HIV CEG. Framework for Guideline Development and Assessment 2014 [17th June 2015]. Available from:

http://www.bashh.org/documents/GUIDELINES FRAMEWORK April 2015.pdf.

3. Benn P, Fisher M, Kulasegaram R, Bashh, Group PGWGCE. UK guideline for the use of post-exposure prophylaxis for HIV following sexual exposure (2011). International journal of STD \& AIDS. 2011;22(12):695-708.

4. Control CfD. Antiretroviral psotexposure prophylaxis after sexual, injection-drug use, or other nonoccupational exposure to HIV in the United States Morbity and Mortality Weekly Reports, 2005 / 54(RR02);1-202005 [17th June 2015]. Available from: http://www.cdc.gov/mmwr/preview/mmwrhtml//rr5402a1.htm.

$5 . \quad$ Organisation WH. Guidelines on post-exposure prophylaxis for HIV and the use of cotrimoxazole prophylaxis for HIV-related infections among adults, adolescents and children. 2014.

6. Medicine ASfH. National guidelines for post-exposure prophylaxis after non-occupational and occupational exposure to HIV 2013 [17th June 2015]. Available from:

http://www.ashm.org.au/Documents/Guide for the Management of Occupational and NonOccupational Post-Exposure Prophylaxis.pdf.

7. $\quad$ Pinto LA, Landay AL, Berzofsky JA, Kessler HA, Shearer GM. Immune response to human immunodeficiency virus (HIV) in healthcare workers occupationally exposed to HIV-contaminated blood. The American journal of medicine. 1997;102(5B):21-4.

8. Spira AI, Marx PA, Patterson BK, Mahoney J, Koup RA, Wolinsky SM, et al. Cellular targets of infection and route of viral dissemination after an intravaginal inoculation of simian

immunodeficiency virus into rhesus macaques. The Journal of experimental medicine. 1996;183(1):215-25.

9. Bourry O, Mannioui A, Sellier P, Roucairol C, Durand-Gasselin L, Dereuddre-Bosquet N, et al. Effect of a short-term HAART on SIV load in macaque tissues is dependent on time of initiation and antiviral diffusion. Retrovirology. 2010;7:78.

10. Grant RM, Wiley JA, Winkelstein W. Infectivity of the human immunodeficiency virus: estimates from a prospective study of homosexual men. The Journal of infectious diseases. 1987;156(1):189-93.

11. Samuel MC, Hessol N, Shiboski S, Engel RR, Speed TP, Winkelstein W, Jr. Factors associated with human immunodeficiency virus seroconversion in homosexual men in three San Francisco cohort studies, 1984-1989. Journal of acquired immune deficiency syndromes. 1993;6(3):303-12.

12. Vittinghoff E, Douglas J, Judson F, McKirnan D, MacQueen K, Buchbinder SP. Per-contact risk of human immunodeficiency virus transmission between male sexual partners. American journal of epidemiology. 1999;150(3):306-11.

13. Mastro TD, Kitayaporn D. HIV type 1 transmission probabilities: estimates from epidemiological studies. AIDS research and human retroviruses. 1998;14 Suppl 3:S223-7.

14. Royce RA, Sena A, Cates W, Jr., Cohen MS. Sexual transmission of HIV. The New England journal of medicine. 1997;336(15):1072-8.

15. Baggaley RF, White RG, Boily MC. HIV transmission risk through anal intercourse: systematic review, meta-analysis and implications for HIV prevention. International journal of epidemiology. 2010;39(4):1048-63.

16. DeGruttola V, Seage GR, 3rd, Mayer KH, Horsburgh CR, Jr. Infectiousness of HIV between male homosexual partners. Journal of clinical epidemiology. 1989;42(9):849-56.

17. Jin F, Jansson J, Law M, Prestage GP, Zablotska I, Imrie JC, et al. Per-contact probability of HIV transmission in homosexual men in Sydney in the era of HAART. Aids. 2010;24(6):907-13. 
18. de Vincenzi I. A longitudinal study of human immunodeficiency virus transmission by heterosexual partners. European Study Group on Heterosexual Transmission of HIV. The New England journal of medicine. 1994;331(6):341-6.

19. Gray RH, Wawer MJ, Brookmeyer R, Sewankambo NK, Serwadda D, Wabwire-Mangen F, et al. Probability of HIV-1 transmission per coital act in monogamous, heterosexual, HIV-1discordant couples in Rakai, Uganda. Lancet. 2001;357(9263):1149-53.

20. Leynaert B, Downs AM, de Vincenzi I. Heterosexual transmission of human immunodeficiency virus: variability of infectivity throughout the course of infection. European Study Group on Heterosexual Transmission of HIV. American journal of epidemiology. 1998;148(1):88-96. 21. Downs AM, De Vincenzi I. Probability of heterosexual transmission of HIV: relationship to the number of unprotected sexual contacts. European Study Group in Heterosexual Transmission of HIV. Journal of acquired immune deficiency syndromes and human retrovirology : official publication of the International Retrovirology Association. 1996;11(4):388-95.

22. Donnelly C, Leisenring W, Kanki $\mathrm{P}$, Awerbuch T, Sandberg S. Comparison of transmission rates of HIV-1 and HIV-2 in a cohort of prostitutes in Senegal. Bulletin of mathematical biology. 1993;55(4):731-43.

23. Hayes RJ, Schulz KF, Plummer FA. The cofactor effect of genital ulcers on the per-exposure risk of HIV transmission in sub-Saharan Africa. The Journal of tropical medicine and hygiene. 1995;98(1):1-8.

24. Peterman TA, Stoneburner RL, Allen JR, Jaffe HW, Curran JW. Risk of human immunodeficiency virus transmission from heterosexual adults with transfusion-associated infections. Jama. 1988;259(1):55-8.

25. del Romero J, Marincovich B, Castilla J, Garcia S, Campo J, Hernando V, et al. Evaluating the risk of HIV transmission through unprotected orogenital sex. Aids. 2002;16(9):1296-7.

26. Ippolito G, Puro V, De Carli G. The risk of occupational human immunodeficiency virus infection in health care workers. Italian Multicenter Study. The Italian Study Group on Occupational Risk of HIV infection. Archives of internal medicine. 1993;153(12):1451-8.

27. Kaplan EH. Modeling HIV infectivity: must sex acts be counted? Journal of acquired immune deficiency syndromes. 1990;3(1):55-61.

28. Control CfD. Case-control study of HIV seroconversion in healthcare workers after percutaneous exposure to HIV-infected blood France, United Kingdom and United States, January 1988-August 1994. Mor Mortal Wkly Rep. 1995;44:929.

29. Cardo DM, Culver DH, Ciesielski CA, Srivastava PU, Marcus R, Abiteboul D, et al. A casecontrol study of HIV seroconversion in health care workers after percutaneous exposure. Centers for Disease Control and Prevention Needlestick Surveillance Group. The New England journal of medicine. 1997;337(21):1485-90.

30. Bell DM. Occupational risk of human immunodeficiency virus infection in healthcare workers: an overview. The American journal of medicine. 1997;102(5B):9-15.

31. Richman KM, Rickman LS. The potential for transmission of human immunodeficiency virus through human bites. Journal of acquired immune deficiency syndromes. 1993;6(4):402-6.

32. Wahn V, Kramer HH, Voit T, Bruster HT, Scrampical B, Scheid A. Horizontal transmission of HIV infection between two siblings. Lancet. 1986;2(8508):694.

33. Gray RH, Wawer MJ. Probability of heterosexual HIV-1 transmission per coital act in subSaharan Africa. The Journal of infectious diseases. 2012;205(3):351-2.

34. Rothenberg RB, Scarlett M, del Rio C, Reznik D, O'Daniels C. Oral transmission of HIV. Aids. 1998;12(16):2095-105.

35. Rottingen JA, Cameron DW, Garnett GP. A systematic review of the epidemiologic interactions between classic sexually transmitted diseases and HIV: how much really is known? Sexually transmitted diseases. 2001;28(10):579-97.

36. Sadiq ST, Taylor S, Kaye S, Bennett J, Johnstone R, Byrne P, et al. The effects of antiretroviral therapy on HIV-1 RNA loads in seminal plasma in HIV-positive patients with and without urethritis. Aids. 2002;16(2):219-25.

37. Gitau RW, Graham SM, Masese LN, Overbaugh J, Chohan V, Peshu N, et al. Effect of acquisition and treatment of cervical infections on HIV-1 shedding in women on antiretroviral therapy. Aids. 2010;24(17):2733-7. 
38. Wald A, Link K. Risk of human immunodeficiency virus infection in herpes simplex virus type 2-seropositive persons: a meta-analysis. The Journal of infectious diseases. 2002;185(1):45-52.

39. Templeton DJ. Male circumcision to reduce sexual transmission of HIV. Current opinion in HIV and AIDS. 2010;5(4):344-9.

40. Auvert B, Taljaard D, Lagarde E, Sobngwi-Tambekou J, Sitta R, Puren A. Randomized, controlled intervention trial of male circumcision for reduction of HIV infection risk: the ANRS 1265 Trial. PLoS medicine. 2005;2(11):e298.

41. Bailey RC, Moses S, Parker CB, Agot K, Maclean I, Krieger JN, et al. Male circumcision for HIV prevention in young men in Kisumu, Kenya: a randomised controlled trial. Lancet. 2007;369(9562):643-56.

42. Gray RH, Kigozi G, Serwadda D, Makumbi F, Watya S, Nalugoda F, et al. Male circumcision for HIV prevention in men in Rakai, Uganda: a randomised trial. Lancet. 2007;369(9562):657-66.

43. Millett GA, Flores SA, Marks G, Reed JB, Herbst JH. Circumcision status and risk of HIV and sexually transmitted infections among men who have sex with men: a meta-analysis. Jama. 2008;300(14):1674-84.

44. Vernazza PL, Troiani L, Flepp MJ, Cone RW, Schock J, Roth F, et al. Potent antiretroviral treatment of HIV-infection results in suppression of the seminal shedding of HIV. The Swiss HIV Cohort Study. Aids. 2000;14(2):117-21.

45. Cu-Uvin S, DeLong AK, Venkatesh KK, Hogan JW, Ingersoll J, Kurpewski J, et al. Genital tract HIV-1 RNA shedding among women with below detectable plasma viral load. Aids. 2010;24(16):2489-97.

46. Tsai CC, Emau P, Follis KE, Beck TW, Benveniste RE, Bischofberger N, et al. Effectiveness of postinoculation (R)-9-(2-phosphonylmethoxypropyl) adenine treatment for prevention of persistent simian immunodeficiency virus SIVmne infection depends critically on timing of initiation and duration of treatment. Journal of virology. 1998;72(5):4265-73.

47. Otten RA, Smith DK, Adams DR, Pullium JK, Jackson E, Kim CN, et al. Efficacy of postexposure prophylaxis after intravaginal exposure of pig-tailed macaques to a human-derived retrovirus (human immunodeficiency virus type 2). Journal of virology. 2000;74(20):9771-5.

48. Le Grand R, Vaslin B, Larghero J, Neidez O, Thiebot H, Sellier P, et al. Post-exposure prophylaxis with highly active antiretroviral therapy could not protect macaques from infection with SIV/HIV chimera. Aids. 2000;14(12):1864-6.

49. Bourry O, Brochard P, Souquiere S, Makuwa M, Calvo J, Dereudre-Bosquet N, et al. Prevention of vaginal simian immunodeficiency virus transmission in macaques by postexposure prophylaxis with zidovudine, lamivudine and indinavir. Aids. 2009;23(4):447-54.

50. Garcia-Lerma JG, Cong ME, Mitchell J, Youngpairoj AS, Zheng Q, Masciotra S, et al. Intermittent prophylaxis with oral truvada protects macaques from rectal SHIV infection. Science translational medicine. 2010;2(14):14ra4.

51. Tomkins S, Ncube F. Occupationally acquired HIV: international reports to December 2002. Euro surveillance : bulletin Europeen sur les maladies transmissibles = European communicable disease bulletin. 2005;10(3):E050310 2.

52. Sperling RS, Shapiro DE, Coombs RW, Todd JA, Herman SA, McSherry GD, et al. Maternal viral load, zidovudine treatment, and the risk of transmission of human immunodeficiency virus type 1 from mother to infant. Pediatric AIDS Clinical Trials Group Protocol 076 Study Group. The New England journal of medicine. 1996;335(22):1621-9.

53. Wade NA, Birkhead GS, Warren BL, Charbonneau TT, French PT, Wang L, et al. Abbreviated regimens of zidovudine prophylaxis and perinatal transmission of the human immunodeficiency virus. The New England journal of medicine. 1998;339(20):1409-14.

54. Schechter M, do Lago RF, Mendelsohn AB, Moreira RI, Moulton LH, Harrison LH, et al. Behavioral impact, acceptability, and HIV incidence among homosexual men with access to postexposure chemoprophylaxis for HIV. Journal of Acquired Immune Deficiency Syndromes: JAIDS. 2004;35(5):519-25.

55. Tostevin A WE, Croxford S, Delpech V, Williams I. Trends in transmitted drug resistance to HIV-1 in the UK since 2010. HIV Medicine. 2015;16 (Suppl. 2):6. 
56. Roland ME, Neilands TB, Krone MR, Katz MH, Franses K, Grant RM, et al. Seroconversion following nonoccupational postexposure prophylaxis against HIV. Clinical infectious diseases : an official publication of the Infectious Diseases Society of America. 2005;41(10):1507-13.

57. Haidari G FS, Fox J, Fitzgerald J, Raffe S, Fisher M et al. . Acute HIV infection after initiation of post-exposure prophylaxis following sexual exposure: reasons, challenges and usggested managment. HIV Medicine. 2015;16 (Suppl. 2)(P35):23.

58. Parkin JM, Murphy M, Anderson J, El-Gadi S, Forster G, Pinching AJ. Tolerability and sideeffects of post-exposure prophylaxis for HIV infection. Lancet. 2000;355(9205):722-3.

59. Evans B, Duggan W, Baker J, Ramsay M, Abiteboul D. Exposure of healthcare workers in England, Wales, and Northern Ireland to bloodborne viruses between July 1997 and June 2000: analysis of surveillance data. Bmj. 2001;322(7283):397-8.

60. Kahn JO, Martin JN, Roland ME, Bamberger JD, Chesney M, Chambers D, et al. Feasibility of postexposure prophylaxis (PEP) against human immunodeficiency virus infection after sexual or injection drug use exposure: the San Francisco PEP Study. The Journal of infectious diseases. 2001;183(5):707-14.

61. Bennett A, Wainwright E, Lord E, Oduru M, Duncan S. The impact of the 2011 postexposure HIV prophylaxis following sexual exposure (PEPSE) guidelines: A regional retrospective audit across three genitourinary centres. HIV Medicine. 2014;15:146.

62. Spice B, Bhaduri S, Sivaram M. An audit of PEPSE in the West Midlands. HIV Medicine. 2014;15:131.

63. Parkash V, Garner A, Gupta N. Evaluation of PEPSE use in a district general hospital genitourinary medicine department. HIV Medicine. 2014;15:148.

64. Awosusi F, Mashal S, O'Connell R. A retrospective audit in a London HIV clinic, assessing the post-exposure prophylaxis for HIV following sexual exposure (PEPSE). HIV Medicine. 2014;15:39-40.

65. Rowley D, O'Bara R, Quinlan M, Clarke S. Twenty-eight days later: Audit of postexposure prophylaxis following sexual exposure (PEPSE) in a community sexual health clinic for men who have sex men. International Journal of STD and AIDS. 2013;24:9-10.

66. Janmohamed K, Bull L, Payne D, Cooper F, Lake C, Nwokolo N, et al. Post exposure prophylaxis following possible exposure to HIV infection: An evaluation of 391 attendances at three central London sexual health clinics. Sexually Transmitted Infections. 2012;88.

67. Day S, Mears A, Bond K, Kulasegaram R. Post-exposure HIV prophylaxis following sexual exposure: a retrospective audit against recent draft BASHH guidance. Sexually Transmitted Infections. 2006;82(3):236-7.

68. Martin JN, Roland ME, Neilands TB, Krone MR, Bamberger JD, Kohn RP, et al. Use of postexposure prophylaxis against HIV infection following sexual exposure does not lead to increases in high-risk behavior. Aids. 2004;18(5):787-92.

69. van der Straten A, Gomez CA, Saul J, Quan J, Padian N. Sexual risk behaviors among heterosexual HIV serodiscordant couples in the era of post-exposure prevention and viral suppressive therapy. Aids. 2000;14(4):F47-54.

70. Waldo CR FK, Dillon B. "Close calls": a teachable moment for long-term behaviour change. . In: Chesney MA AM, editor. Innovative Approaches to Health Psychology: Prevenetion and Treatment lessons from AIDS Washington: APA; 2002.

71. Sheena McCormack SF, Martin Fisher. Updated BHIVA-BASHH Position Statement on PrEP in the UK 2015 [8th July 2015]. Available from:

http://www.bashh.org/documents/PreP BHIVA BASHH Update 14June15 for consultation.pdf.

72. Smith DK, Herbst JH, Zhang X, Rose CE. Condom effectiveness for HIV prevention by consistency of use among men who have sex with men in the United States. Journal of acquired immune deficiency syndromes. 2015;68(3):337-44.

73. Greub G, Maziero A, Burgisser P, Telenti A, Francioli P. Spare post-exposure prophylaxis with round-the-clock HIV testing of the source patient. Aids. 2001;15(18):2451-2.

74. Greub G, Gallant S, Zurn P, Vannotti M, Burgisser P, Francioli P, et al. Spare nonoccupational HIV post-exposure prophylaxis by active contacting and testing of the source person. Aids. 2002;16(8):1171-6. 
75. Quinn TC, Wawer MJ, Sewankambo N, Serwadda D, Li C, Wabwire-Mangen F, et al. Viral load and heterosexual transmission of human immunodeficiency virus type 1. Rakai Project Study Group. The New England journal of medicine. 2000;342(13):921-9.

76. Donnell D, Baeten JM, Kiarie J, Thomas KK, Stevens W, Cohen CR, et al. Heterosexual HIV-1 transmission after initiation of antiretroviral therapy: a prospective cohort analysis. Lancet. 2010;375(9731):2092-8.

77. Attia S, Egger M, Muller M, Zwahlen M, Low N. Sexual transmission of HIV according to viral load and antiretroviral therapy: systematic review and meta-analysis. Aids. 2009;23(11):1397-404.

78. Cohen MS, Chen YQ, McCauley M, Gamble T, Hosseinipour MC, Kumarasamy N, et al. Prevention of HIV-1 infection with early antiretroviral therapy. New England Journal of Medicine. 2011;365(6):493-505.

79. Rodger A BT, Cambiano V, Vernazza P, Estrada V, Van Lunzen J, editor HIV Transmission Risk Through Condomless Sex If HIV+ Partner on Suppressive ART: PARTNER study. CROI; 2014 March; Boston, USA. .

80. Abdala N, Stephens PC, Griffith BP, Heimer R. Survival of HIV-1 in syringes. Journal of acquired immune deficiency syndromes and human retrovirology : official publication of the International Retrovirology Association. 1999;20(1):73-80.

81. Kim JC, Martin LJ, Denny L. Rape and HIV post-exposure prophylaxis: addressing the dual epidemics in South Africa. Reproductive health matters. 2003;11(22):101-12.

82. Platt L, Jolley E, Rhodes T, Hope V, Latypov A, Reynolds L, et al. Factors mediating HIV risk among female sex workers in Europe: a systematic review and ecological analysis. BMJ open. 2013;3(7).

83. UNAIDS. The GAP report 2014. 2014.

84. Farrugia Parsons B, Fisher K, Cordery D, Couldwell D. Counselling improves follow-up HIV testing at Week 6 for HIV postexposure prophylaxis recipients. Sexual Health. 2013;10(3):288-9. 85. Bentz L, Enel P, Dunais B, Durant J, Poizot-Martin I, Tourette-Turgis C, et al. Evaluating counseling outcome on adherence to prophylaxis and follow-up after sexual HIV-risk exposure: a randomized controlled trial. AIDS Care. 2010;22(12):1509-16.

86. James B Whitney AlH, Srisowmya Sanisetty, Pablo Penaloza-MacMaster, Jinyan Liu, Mayuri Shetty. Rapid seeding of the viral reservoir prior to SIV viraemia in rhesus monkeys. Nature. 2014;000:1-4.

87. O'Keeffe C, Nwokolo N, Whitlock G. Does dropping day 5 PEP follow-up affect other outcomes? HIV Medicine. 2014;15:124-5.

88. Society EAC. EACS Treatment Guidelines V7.1 2014 [22nd June 2015]. Available from: http://www.eacsociety.org/guidelines/eacs-guidelines/eacs-guidelines.html.

89. Services DoHaH. Guidelines for the use of antitretoviral agents in HIV-1 infected adults and adolescents 2014. Available from:

https://aidsinfo.nih.gov/contentfiles/lvguidelines/adultandadolescentgl.pdf.

90. Taylor S, Davies S. Antiretroviral drug concentrations in the male and female genital tract: implications for the sexual transmission of HIV. Current opinion in HIV and AIDS. 2010;5(4):335-43.

91. Baeten JM, Donnell D, Ndase P, Mugo NR, Campbell JD, Wangisi J, et al. Antiretroviral prophylaxis for HIV prevention in heterosexual men and women. The New England journal of medicine. 2012;367(5):399-410.

92. Grant RM, Lama JR, Anderson PL, McMahan V, Liu AY, Vargas L, et al. Preexposure chemoprophylaxis for HIV prevention in men who have sex with men. The New England journal of medicine. 2010;363(27):2587-99.

93. McCormack S DD, editor Pragmatic Open-Label Randomised Trial of Preexposure Prophylaxis: The PROUD study. Conference of Retroviruses and Opportunistic Infections; 2015 February 23-26 2015; Seattle.

94. Molina JM CC, Charreau I, Meyer L, Spire B, Pialoux G et al. , editor On Demand PrEP With Oral TDF-FTC in MSM: Results of the ANRS Ipergay Trial. Conference on retroviruses and opportuisitc infections; 2015 February 23-26 2015; Seattle, USA.

95. Riddler SA, Haubrich R, DiRienzo AG, Peeples L, Powderly WG, Klingman KL, et al. Classsparing regimens for initial treatment of HIV-1 infection. The New England journal of medicine. 2008;358(20):2095-106. 
96. Rockstroh JK, Lennox JL, Dejesus E, Saag MS, Lazzarin A, Wan H, et al. Long-term treatment with raltegravir or efavirenz combined with tenofovir/emtricitabine for treatment-naive human immunodeficiency virus-1-infected patients: 156-week results from STARTMRK. Clinical infectious diseases : an official publication of the Infectious Diseases Society of America. 2011;53(8):807-16.

97. Lennox JL, Landovitz RJ, Ribaudo HJ, Ofotokun I, Na LH, Godfrey C, et al. Efficacy and tolerability of 3 nonnucleoside reverse transcriptase inhibitor-sparing antiretroviral regimens for treatment-naive volunteers infected with HIV-1: a randomized, controlled equivalence trial. Annals of internal medicine. 2014;161(7):461-71.

98. McAllister J, Read P, McNulty A, Tong WWY, Ingersoll A, Carr A. Raltegravir-emtricitabinetenofovir as HIV nonoccupational post-exposure prophylaxis in men who have sex with men: safety, tolerability and adherence. HIV Medicine. 2014;15(1):13-22.

99. Annandale D, Richardson C, Fisher M, Richardson D. Raltegravir-based post-exposure prophylaxis (PEP): A safe, well-tolerated alternative regimen. Journal of the International AIDS Society. 2012;15:132.

100. Annandale D, Richardson C, Fisher M, Richardson D. Raltegravir: Alternative postexposure prophylaxis regimen? International Journal of STD and AIDS. 2013;24:4.

101. Leal L LA, Torres B, Inciarte A, Lucero C, Mallolas J, editor Tenofovir/Emtricitabine Plus LPV/r vs MVC or Raltegravir for PEP: 2 Randomized Trials. Conference on Retroviruses and Opportunisitic Infections; 2015 23-26th Febraury 2015; Seattle, USA.

102. Patel SM, Johnson S, Belknap SM, Chan J, Sha BE, Bennett C. Serious adverse cutaneous and hepatic toxicities associated with nevirapine use by non-HIV-infected individuals. Journal of Acquired Immune Deficiency Syndromes: JAIDS. 2004;35(2):120-5.

103. Madruga JV, Cahn P, Grinsztejn B, Haubrich R, Lalezari J, Mills A, et al. Efficacy and safety of TMC125 (etravirine) in treatment-experienced HIV-1-infected patients in DUET-1: 24-week results from a randomised, double-blind, placebo-controlled trial. Lancet. 2007;370(9581):29-38. 104. Lazzarin A, Campbell T, Clotet B, Johnson M, Katlama C, Moll A, et al. Efficacy and safety of TMC125 (etravirine) in treatment-experienced HIV-1-infected patients in DUET-2: 24-week results from a randomised, double-blind, placebo-controlled trial. Lancet. 2007;370(9581):39-48. 105. Scrivener J, McOwan A, Griffiths T, Stuart D. Recreational drug use among genitourinary medicine attendees: Implications for service delivery. International Journal of STD and AIDS. 2013;24:37-8.

106. Compendium EM. Summary of Product Characteristics for Kaletra [17th June 2015]. Available from: https://www.medicines.org.uk/emc/medicine/18442.

107. Diaz-Brito V, Leon A, Knobel H, Peraire J, Domingo P, Clotet B, et al. Post-exposure prophylaxis for HIV infection: a clinical trial comparing lopinavir/ritonavir versus atazanavir each with zidovudine/lamivudine. Antivir Ther. 2012;17(2):337-46.

108. Fatkenheuer G, Jung N, Jessen H, Stoehr A, Arasteh K, Bogner J, et al. Darunavir(DRV)/rBased PEP Versus Standard of Care (SOC) - the Randomized PEPDar Study. Topics in Antiviral Medicine. 2014;22(e-1):497.

109. Massud I, Aung W, Martin A, Bachman S, Mitchell J, Aubert R, et al. Lack of prophylactic efficacy of oral maraviroc in macaques despite high drug concentrations in rectal tissues. Journal of virology. 2013;87(16):8952-61.

110. A Milinkovic PB, A Arenas-Pinto, N Brima, A Copas, A Clarke et al. . Randomised controlled trial of the tolerability and completion of maraviroc compared to Kaletra ${ }^{\circledR}$ in combination with Truvada ${ }^{\circledR}$ for HIV post exposure prophylaxis (MiPEP Trial). European AIDS Clinical Society; Barcelona2015.

111. Authority MHR. Domperidone: risks of cardiac side effects - indication restricted to nausea and vomiting, mew contraindications, and reduced dose and duration of use. Drug Safety Update. 2014;7(10):A1.

112. Characteristics RSoP. Electronic Medicines Compendium [22nd June 2015]. Available from: http://www.medicines.org.uk/emc/medicine/20484/SPC/.

113. Mayer KH, Mimiaga MJ, Gelman M, Grasso C. Raltegravir, tenofovir DF, and emtricitabine for postexposure prophylaxis to prevent the sexual transmission of HIV: safety, tolerability, and adherence. Journal of Acquired Immune Deficiency Syndromes: JAIDS. 2012;59(4):354-9. 
114. Vispo E, Mena A, Maida I, Blanco F, Cordoba M, Labarga P, et al. Hepatic safety profile of raltegravir in HIV-infected patients with chronic hepatitis $\mathrm{C}$. The Journal of antimicrobial chemotherapy. 2010;65(3):543-7.

115. Schleenvoigt BT, Fobiwe JP, Keller PM, Hagel S, Pletz MW. HIV post exposure prophylaxis induced bicytopenia: a case report. AIDS research and therapy. 2014;11(1):11.

116. de Vrieze NHN, van Rooijen MS, van de Loeff MS, de Vries HJC. Additional gonorrhea and Chlamydia Infections found with rapid follow-up screening in men who have sex with men with an indication for HIV postexposure prophylaxis. Sexually transmitted diseases. 2014;41(8):515-7.

117. Gary Brook SB, Ranjababu Kulasegaram R, Adele Torkington, David Mutimer, Elizabeth Hodges. United Kingdom National Guideline on the Management of the Viral 1 Hepatitides A, B \& C 20152015 [8th July 2015]. Available from:

http://www.bashh.org/BASHH/Guidelines/Guidelines/BASHH/Guidelines/Guidelines.aspx.

118. Cresswell FV, Fisher M, Hughes DJ, Shaw SG, Homer G, Hassan-Ibrahim MO. Hepatitis C core antigen testing: a reliable, quick, and potentially cost-effective alternative to hepatitis $C$ polymerase chain reaction in diagnosing acute hepatitis $C$ virus infection. Clinical infectious diseases : an official publication of the Infectious Diseases Society of America. 2015;60(2):263-6. 119. Compendium EM. Truvada Summary of Product Characteristics 2015 [1st June 2015]. Available from: https://www.medicines.org.uk/emc/medicine/15826.

120. Jackson A, Moyle G, Watson V, Tjia J, Ammara A, Back D, et al. Tenofovir, emtricitabine intracellular and plasma, and efavirenz plasma concentration decay following drug intake cessation: implications for HIV treatment and prevention. Journal of acquired immune deficiency syndromes. 2013;62(3):275-81.

121. Hawkins T, Veikley W, St Claire RL, 3rd, Guyer B, Clark N, Kearney BP. Intracellular pharmacokinetics of tenofovir diphosphate, carbovir triphosphate, and lamivudine triphosphate in patients receiving triple-nucleoside regimens. Journal of acquired immune deficiency syndromes. 2005;39(4):406-11.

122. England N. Specialised Services Circular - Pre-Exposure Prophylaxis (PrEP) to prevent HIV: clarification of commissioning position 2015 [1st June 2015]. Available from:

http://www.bashh.org/documents/SSC1516 Position regarding PrEP April 2015.pdf.

123. Writing G, Williams I, Churchill D, Anderson J, Boffito M, Bower M, et al. British HIV Association guidelines for the treatment of HIV-1-positive adults with antiretroviral therapy 2012 (Updated November 2013. All changed text is cast in yellow highlight.). HIV Med. 2014;15 Suppl 1:1-85.

124. Hamlyn E, Ewings FM, Porter K, Cooper DA, Tambussi G, Schechter M, et al. Plasma HIV viral rebound following protocol-indicated cessation of ART commenced in primary and chronic HIV infection. PloS one. 2012;7(8):e43754.

125. AIDS EAGo. HIV post-exposure prophylaxis: guidance from the UK Chief Medical Officers' Expert Advisory Group on AIDS (2008) 2008 [12th July 2015]. Available from: https://www.gov.uk/government/uploads/system/uploads/attachment data/file/203139/HIV postexposure prophylaxis.pdf.

126. de Silva S, Miller RF, Walsh J. Lack of awareness of HIV post-exposure prophylaxis among HIV-infected and uninfected men attending an inner London clinic. International journal of STD \& AIDS. 2006;17(9):629-30.

127. Joshi M, Basra A, Webb H, McCormick C, Pakianathan M. Awareness of post-exposure prophylaxis after sexual exposure (PEPSE) in patients attending an inner city HIV treatment centre. HIV Medicine. 2012;13:85.

128. Pugh E, Pakianathan M, McCormick C, Webb H, Korley K, Patel S. The sexual health behaviour of HIV positive patients in an urban UK cohort. HIV Medicine. 2012;13:17.

129. Roedling S, Reeves I, Copas AJ, Beattie A, Edwards SG, Fisher M, et al. Changes in the provision of post-exposure prophylaxis for HIV after sexual exposure following introduction of guidelines and publicity campaigns. International journal of STD \& AIDS. 2008;19(4):241-2.

130. Joshi M, Basra A, McCormick C, Webb H, Pakianathan M. Post-exposure prophylaxis after sexual exposure (PEPSE) awareness in an HIV-positive cohort. International journal of STD \& AIDS. 2014;25(1):67-9. 
131. Pinkerton SD, Holtgrave DR. How HIV treatment advances affect the cost-effectiveness of prevention. Medical decision making : an international journal of the Society for Medical Decision Making. 2000;20(1):89-94.

132. Nakagawa F, Miners A, Smith CJ, Simmons R, Lodwick RK, Cambiano V, et al. Projected Lifetime Healthcare Costs Associated with HIV Infection. PloS one. 2015;10(4):e0125018.

133. Pinkerton SD, Martin JN, Roland ME, Katz MH, Coates TJ, Kahn JO. Cost-effectiveness of postexposure prophylaxis after sexual or injection-drug exposure to human immunodeficiency virus. Archives of internal medicine. 2004;164(1):46-54.

134. Pinkerton SD, Martin JN, Roland ME, Katz MH, Coates TJ, Kahn JO. Cost-effectiveness of HIV postexposure prophylaxis following sexual or injection drug exposure in 96 metropolitan areas in the United States. Aids. 2004;18(15):2065-73.

135. Guinot D, Ho MT, Poynten IM, McAllister J, Pierce A, Pell C, et al. Cost-effectiveness of HIV nonoccupational post-exposure prophylaxis in Australia. HIV Medicine. 2009;10(4):199-208.

136. Bryant J, Baxter L, Hird S. Non-occupational postexposure prophylaxis for HIV: a systematic review. Health technology assessment. 2009;13(14):iii, ix-x, 1-60. 
Table 1: Estimated HIV prevalence (diagnosed and undiagnosed infection) in adults aged 15-59 years in the UK in 2014

\begin{tabular}{lll}
\hline Population group (aged 15-59 years) & Men & HIV prevalence (\%) \\
& & Women \\
\hline $\begin{array}{l}\text { Men who have sex with men (MSM) } \\
\quad \text { UK }\end{array}$ & 5.9 & - \\
$\quad$ London & 12.5 & - \\
Brighton & 13.7 & \\
Manchester & 8.6 & - \\
$\quad$ Elsewhere in the UK & 3.8 & \\
Heterosexuals & & 7.1 \\
$\quad$ Black African Ethnicity & 4.1 & 0.06 \\
$\quad$ Non Black African Ethnicity & 0.06 & $0.67-1.1$ \\
Injecting drug users (IDU) & $0.67-1.1$ & \\
\hline
\end{tabular}

\footnotetext{
‡ These data are for England and Wales only

${ }^{\dagger}$ The prevalence of HIV among MSM varies across the UK and is higher in metropolitan areas with large MSM populations $\mathrm{s}^{6,7}$

Prevalence estimates were obtained at:

https://www.gov.uk/government/uploads/system/uploads/attachment data/file/401662/2014 P

HE HIV annual report draft Final 07-01-2015.pdf (page 8, figure 1)

https://www.gov.uk/government/uploads/system/uploads/attachment data/file/475712/Shooting U p 2015 FINAL.pdf
} 
Table 2 Risk of HIV transmission per exposure from a known HIV-positive individual not on ART

\begin{tabular}{|l|l|c|}
\hline Type of exposure & $\begin{array}{l}\text { Estimated risk of HIV } \\
\text { transmission per exposure } \\
\text { from a known HIV-positive } \\
\text { individual not on ART }\end{array}$ & References \\
\hline Receptive anal intercourse & 1 in 90 & $(10-16)$ \\
\hline \multicolumn{1}{|c|}{ Receptive anal intercourse with ejaculation } & 1 in 65 & $(10-17)$ \\
\hline Receptive anal intercourse no ejaculation & 1 in 170 & $(17)$ \\
\hline Insertive anal intercourse & 1 in 666 & $(10,12,13,18)$ \\
\hline \multicolumn{1}{|c|}{ Insertive anal intercourse not circumcised } & 1 in 161 & $(17)$ \\
\hline Insertive anal intercourse and circumcised & 1 in 909 & $(17)$ \\
\hline Receptive vaginal intercourse & 1 in 1000 & $(10,15,19-25)$ \\
\hline Insertive vaginal intercourse & 1 in 1,219 & $(14,15,19-25)$ \\
\hline Semen splash to eye & $<1$ in 10,000 & $(26)$ \\
\hline Receptive oral sex (giving fellatio) & $<1$ in 10,000 & $(13,20,25,27)$ \\
\hline Insertive oral sex (receiving fellatio) & $<1$ in 10,000 & $(12,25)$ \\
\hline Blood transfusion (one unit) & 1 in 1 & $(28)$ \\
\hline Needlestick injury & 1 in 333 & $(27,29,30)$ \\
\hline $\begin{array}{l}\text { Sharing injecting equipment (includes } \\
\text { chemsex) }\end{array}$ & 1 in 149 & $(26)$ \\
\hline Human bite & $<1$ in 10,000 & \\
\hline
\end{tabular}




\section{Box 1: Factors increasing the risk of HIV transmission:}

1. A high plasma HIV viral load (VL) in the source - with each $\log _{10}$ increase in plasma HIV RNA the per-act risk of transmission in increased 2.9 fold [95\% confidence interval $(\mathrm{Cl}) 2.2-3.8$ ] (33). This may be particularly relevant during primary HIV infection (20).

2. Breaches in the mucosal barrier such as mouth or genital ulcer disease and anal or vaginal trauma following sexual assault or first intercourse $(34,35)$.

3. Menstruation or other bleeding - theoretical risk only

4. Sexually transmitted infections in HIV positive individuals not on $\operatorname{ART}(36,37)$ or HIV negative individuals with genital ulcer disease (38).

5. Ejaculation - Among a community cohort of men who have sex with men (MSM) the risk of HIV acquisition per episode of unprotected receptive anal intercourse with and without ejaculation was estimated to be $1.43 \%$ (95\% confidence interval $[\mathrm{Cl}] 0.48-2.85)$ and $0.65 \%(95 \% \mathrm{Cl} 0.15-1.53)$, respectively (17).

6. Non-circumcision - circumcision has been shown to significantly reduce HIV acquisition among heterosexual men in high prevalence countries (39-42). In 2008 a meta-analysis of observational studies in MSM suggests circumcision has little impact upon HIV acquisition (43). However, since then the risk of HIV acquisition per episode of unprotected insertive anal intercourse in circumcised men was estimated to be $0.11 \%(95 \% \mathrm{Cl} 0.02-0.24)$ versus $0.62 \%(95 \% \mathrm{Cl}$ $0.07-1.68$ ) in uncircumcised men in a community cohort of MSM in Australia (17).

7. Discordant HIV viral load in the genital tract - In general, the genital tract viral load is undetectable when the plasma viral load is undetectable. When this is not the case the viral load in the genital tract is usually low $(44,45)$. 
Table 3: Summary table of PEPSE prescribing recommendations

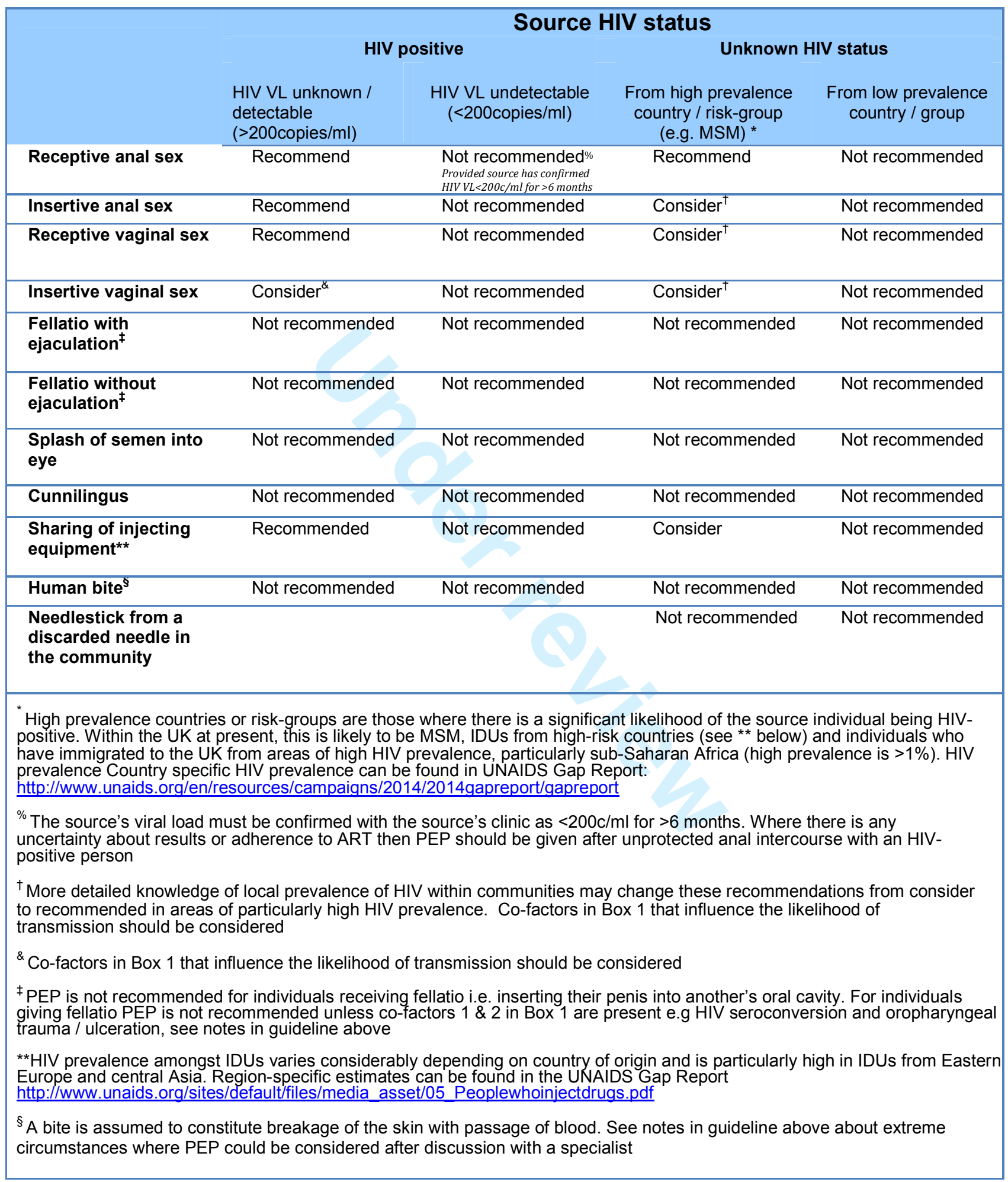




\section{Box 2: Items to discuss with individual initiating PEPSE:}

1. The rationale for PEPSE

2. The lack of conclusive data for the efficacy of PEPSE

3. The potential risks and side-effects of PEPSE

4. The arrangement for early follow-up with an HIV/GU medicine clinician

5. Pre-test discussion and HIV test $\left(4^{\text {th }}\right.$ generation laboratory test)

6. The need to continue PEPSE for 28 days if the baseline result is negative

7. The need to have a follow-up HIV test 8-12 weeks post-exposure

8. The need for safer sex for the following two months

9. Emergency contraception should be discussed if relevant

10. Coping strategies, assessment of vulnerabilities and social support

11. For patients concerned about sexual risk-taking health Sexual Health Advisers can offer ongoing risk reduction work or referral to psychology 
Table 4. Recommended combinations for PEP

\begin{tabular}{|c|c|c|}
\hline & NRTI Backbone (2 medications) & Third agent \\
\hline $\begin{array}{l}\text { Recommended } \\
\text { combination }\end{array}$ & $\begin{array}{l}\text { Truvada }^{\&} \text { one tablet once daily } \\
\text { (tenofovir disoproxil fumarate } \\
245 \mathrm{mg} \text {, emtricitabine } 200 \mathrm{mg} \text { ) }\end{array}$ & $\begin{array}{l}\text { Raltegravir } 400 \mathrm{mg} \text { every } \\
12 \text { hours* }\end{array}$ \\
\hline Alternative $1^{\#}$ & $\begin{array}{l}\text { Combivir (Zidovudine } 250 \mathrm{mg} \\
\text { twice daily plus lamivudine } 150 \mathrm{mg} \\
\text { twice daily) }\end{array}$ & $\begin{array}{l}\text { Protease inhibitor } \\
\text { Kaletra (lopinavir } 200 \mathrm{mg} \text {, } \\
\text { ritonavir } 50 \mathrm{mg}^{* *} \text { ) Two } \\
\text { tablets twice daily } \\
\text { OR } \\
\text { Darunavir } 800 \mathrm{mg} \text { once } \\
\text { daily + ritonavir 100mg** } \\
\text { once daily } \\
\text { OR } \\
\text { Atazanavir } 300 \mathrm{mg} \text { once } \\
\text { daily + ritonavir } 100 \mathrm{mg}^{\star *} \\
\text { once daily } \\
\text { OR } \\
\text { Dolutegravir } 50 \mathrm{mg} \text { once } \\
\text { daily } \$\end{array}$ \\
\hline \multicolumn{3}{|c|}{$\begin{array}{l}{ }^{*} \text { Antacids and multivitamins (products containing metal cations e.g. magnesium / aluminium, which can } \\
\text { chelate and reduce the absorption of raltegravir) should be avoided where possible during PEP, see } \\
\text { appendix A. An alternative non-interacting medication may be considered. See appendix A about co- } \\
\text { administration of rifampicin }\end{array}$} \\
\hline \multicolumn{3}{|c|}{$\begin{array}{l}\text { \# Combivir may be preferred to Truvada in patients with abnormal renal function at baseline. Lamivudine } \\
\text { may require dose-adjustment depending on renal function. }\end{array}$} \\
\hline \multicolumn{3}{|c|}{$\begin{array}{l}{ }^{* *} \text { Significant drug-drug interactions can occur with boosted protease inhibitors, seek expert advice from } \\
\text { a HIV specialist pharmacist, local medicines and poisons information centre or use the website } \\
\text { www.hiv-druginteractions.org }\end{array}$} \\
\hline \multicolumn{3}{|c|}{$\begin{array}{l}{ }^{\$} \text { At the time of publication there are no data on the use of dolutegravir as PEP but it is anticipated to be } \\
\text { well-tolerated }\end{array}$} \\
\hline \multicolumn{3}{|c|}{$\begin{array}{l}\text { Swallowing difficulty - Truvada can be disintegrated in } 100 \mathrm{ml} \text { of water or orange juice and taken } \\
\text { immediately. Kaletra can be used as an alternative to raltegravir and is commercially available as an } \\
\text { oral solution; the recommended dosage is } 5 \mathrm{ml} \text { twice daily with food. }\end{array}$} \\
\hline
\end{tabular}


Table 5: Recommended monitoring during PEP course and follow-up

\begin{tabular}{|c|c|c|}
\hline & Baseline & $\begin{array}{l}\text { 8-12 weeks post- } \\
\text { exposure }\end{array}$ \\
\hline HIV & $\checkmark$ & $\checkmark$ \\
\hline $\begin{array}{l}\text { Hep B sAg } \\
\text { (if no history of } \\
\text { vaccination) }\end{array}$ & $\checkmark$ & only if not immune \\
\hline $\begin{array}{l}\text { Syphilis, } \\
\text { Hep C, Hep } \\
\text { B immunity }\end{array}$ & \multicolumn{2}{|c|}{$\begin{array}{c}\text { As per local clinic policy or BASHH guidelines } \\
\underline{\text { http://www.bashh.org/BASHH/Guidelines/Guidelines/BASHH/Guidelines/Guidelines. }} \\
\underline{\text { aspx }}\end{array}$} \\
\hline $\begin{array}{l}\text { STI testing } \\
\text { (as appropriate } \\
\text { per local clinic } \\
\text { policy) }\end{array}$ & $\checkmark$ & If further UPSI has taken place \\
\hline Creatinine & $\begin{array}{l}\text { Only if abnormalities at } \\
\text { baseline }\end{array}$ & \\
\hline $\begin{array}{l}\text { Alanine } \\
\text { transaminas } \\
\text { e (ALT) }\end{array}$ & $\begin{array}{l}\text { Only if abnormalities at } \\
\text { baseline, Hep B/C co- } \\
\text { infected or on Kaletra }\end{array}$ & \\
\hline $\begin{array}{l}\text { Urinalysis or } \\
\text { uPCR }\end{array}$ & $\checkmark \quad \begin{array}{l}\text { Only if abnormalities at } \\
\text { baseline }\end{array}$ & $\begin{array}{c}\text { if abnormalities at baseline or } 2 \\
\text { weeks }\end{array}$ \\
\hline $\begin{array}{l}\text { Pregnancy } \\
\text { test }\end{array}$ & $\checkmark \quad$ If appropriate & If appropriate \\
\hline CK & $\begin{array}{l}\text { Only if symptomatic of } \\
\text { myositis }\end{array}$ & \\
\hline
\end{tabular}


Table 6: Guidance on missed doses of PEPSE (2D)

\begin{tabular}{|lll|}
\hline Scenario & Recommendation & Comments \\
\hline $\begin{array}{l}\text { 244 hours elapsed } \\
\text { since last dose }\end{array}$ & $\begin{array}{l}\text { Take missed doses } \\
\text { immediately and subsequent } \\
\text { doses at usual time }\end{array}$ & $\begin{array}{l}\text { Reinforce importance of adherence and re-evaluate } \\
\text { motivation to continue PEP }\end{array}$ \\
\hline $\begin{array}{l}\text { 24-48 hours elapsed } \\
\text { since last dose }\end{array}$ & Continue PEPSE & $\begin{array}{l}\text { Reinforce importance of adherence and re-evaluate } \\
\text { motivation to continue PEP }\end{array}$ \\
\hline $\begin{array}{l}\mathbf{> 4 8} \text { hours since last } \\
\text { dose }\end{array}$ & Recommend stop PEPSE & \\
\hline
\end{tabular}


Table 7. Reported use of PEPSE via GUMCAD 2011-2013

\begin{tabular}{lrrr} 
& $\mathbf{2 0 1 1}$ & $\mathbf{2 0 1 2}$ & $\mathbf{2 0 1 3}$ \\
\hline Male Heterosexual & 677 & 974 & 988 \\
MSM & 2,386 & 3,763 & 4,237 \\
Women heterosexual & 723 & 940 & 982 \\
Women who have sex with women & 20 & 24 & 22 \\
Total & $\mathbf{3 , 9 7 5}$ & $\mathbf{5 , 8 6 2}$ & $\mathbf{6 , 4 1 0}$ \\
\hline
\end{tabular}




\section{APPENDIX A}

\section{POTENTIAL FOR DRUG-DRUG INTERACTIONS}

When prescribing PEP it is essential to ensure that the potential for drug-drug interactions is considered, therefore an accurate patient medication history should be reconciled. Clinicians are advised to liaise with a HIV specialist pharmacist and/or use Liverpool Drug Interaction website (http://www.hiv-druginteractions.org) for this purpose. Examples of relevant drug-drug interactions between raltegravir and other medications are shown in Appendix A. Consideration should be given to the use of over-the-counter and recreational drugs.

\section{DRUG-DRUG INTERACTIONS WITH TRUVADA}

There are no significant drug-drug interactions although caution should be applied when Truvada is co-administered with other potentially nephrotoxic agents. Enhanced renal monitoring may be warranted in this situation.

\section{DRUG-DRUG INTERACTIONS WITH RALTEGRAVIR}

In vitro studies indicate that raltegravir is not a substrate of cytochrome P450 (CYP) enzymes, does not inhibit CYP1A2, CYP2B6, CYP2C8, CYP2C9, CYP2C19, CYP2D6 or CYP3A, does not induce CYP3A4 and does not inhibit P-glycoproteinmediated transport. Based on these data, raltegravir is not expected to affect the pharmacokinetics of medicinal products that are substrates of these enzymes or Pglycoprotein.

Co-administration of raltegravir with aluminium and magnesium antacids resulted in reduced raltegravir plasma levels. Cationic complexation results in reduced absorption of raltegravir therefore co-administration of raltegravir with antacids and multivitamins should be avoided where possible during PEP. Caution and appropriate advice as outlined in appendix A should be given if the patient is taking calcium or iron preparations.

Raltegravir is eliminated mainly by metabolism via a UGT1A1-mediated glucuronidation pathway. Given that raltegravir is metabolised primarily via UGT1A1, caution should be used when co-administering raltegravir with strong inducers of UGT1A1 (e.g. rifampicin). Rifampicin reduces plasma levels of raltegravir; the impact on the efficacy of raltegravir is unknown. However, if co-administration with rifampicin is unavoidable, a doubling of the dose of raltegravir can be considered in adults. The 
impact of other strong inducers of drug metabolising enzymes, such as phenytoin and phenobarbital, on UGT1A1 is unknown. Less potent inducers (e.g., efavirenz, nevirapine, etravirine, rifabutin, glucocorticoids, St. John's wort, pioglitazone) may be used with the recommended dose of raltegravir.

The table below outlines the potential drug-drug interactions with raltegravir and commonly used medication, or where interactions are significant. Please seek advice from a specialist HIV pharmacist and/or use Liverpool Drug Interaction website http://www.hiv-druginteractions.org

\begin{tabular}{|c|c|c|}
\hline Medication & Problem & Advice \\
\hline \multicolumn{3}{|l|}{ Metal Cations } \\
\hline $\begin{array}{l}\text { Aluminium/magnesium hydroxide and } \\
\text { calcium carbonate antacids }\end{array}$ & $\begin{array}{l}\text { Co-administration of raltegravir with antacids } \\
\text { resulted in reduced raltegravir plasma levels. }\end{array}$ & $\begin{array}{l}\text { Co-administration of raltegravir with antacids is NOT } \\
\text { recommended. } \\
\text { Stop antacid and prescribe PPI/H2 antagonist if } \\
\text { required }\end{array}$ \\
\hline Calcium supplements & $\begin{array}{l}\text { Caution is recommended as raltegravir } \\
\text { concentrations may be reduced }\end{array}$ & $\begin{array}{l}\text { No dose adjustment is required but should be taken } \\
\text { well separated in time from the administration of } \\
\text { raltegravir (At least } 4 \text { hours after or } 6 \text { hours before). }\end{array}$ \\
\hline Iron supplements & $\begin{array}{l}\text { The effect of cationic complexation resulting in } \\
\text { reduced absorption cannot be excluded }\end{array}$ & $\begin{array}{l}\text { Iron supplements should be taken well separated in } \\
\text { time from the administration of raltegravir (At least } 4 \\
\text { hours after or } 6 \text { hours before). }\end{array}$ \\
\hline \multicolumn{3}{|l|}{ Multi-vitamins } \\
\hline $\begin{array}{l}\text { Multivitamin preparations may contain } \\
\text { polyvalent cations. The effect of cationic } \\
\text { complexation resulting in reduced } \\
\text { absorption cannot be excluded. }\end{array}$ & $\begin{array}{l}\text { Caution is recommended as raltegravir } \\
\text { concentrations may be reduced. }\end{array}$ & $\begin{array}{l}\text { Multivitamins should be taken well separated in time } \\
\text { from the administration of raltegravir (At least } 4 \text { hours } \\
\text { after or } 6 \text { hours before). Or ideally avoid if possible. }\end{array}$ \\
\hline \multicolumn{3}{|l|}{ Anticonvulsants } \\
\hline Carbamazepine & $\begin{array}{l}\text { Coadministration has not been studied but could } \\
\text { potentially decrease raltegravir concentrations as it } \\
\text { is mainly glucuronidated by UGT1A1 and in vitro } \\
\text { data suggest that carbamazepine induces UGT1A1 }\end{array}$ & No dose adjustment recommended \\
\hline Phenobarbitone/phenytoin & $\begin{array}{l}\text { The impact of phenobarbital on UGT1A1 is } \\
\text { unknown. }\end{array}$ & No dose adjustment recommended \\
\hline \multicolumn{3}{|l|}{ Antimicrobials } \\
\hline Rifabutin & $\begin{array}{l}\text { Coadministration of raltegravir ( } 400 \mathrm{mg} \text { twice daily) } \\
\text { and rifabutin ( } 300 \mathrm{mg} \text { once daily) increased } \\
\text { raltegravir AUC (19\%) and Cmax (39\%), but } \\
\text { decreased Ctrough (20\%). }\end{array}$ & $\begin{array}{l}\text { These changes were not deemed clinically significant } \\
\text { and no dose adjustment is required. }\end{array}$ \\
\hline Rifampicin & $\begin{array}{l}\text { raltegravir } \mathrm{AUC} \downarrow 40 \% \\
\text { raltegravir } \mathrm{C}_{12 \mathrm{hr}} \downarrow 61 \% \\
\text { raltegravir } \mathrm{C}_{\max } \downarrow 38 \% \\
\text { (UGT1A1 induction) }\end{array}$ & $\begin{array}{l}\text { Rifampicin reduces plasma levels of raltegravir. If co- } \\
\text { administration with rifampicin is unavoidable, a } \\
\text { doubling of the dose of raltegravir to } \mathbf{8 0 0 m g} \text { every } \\
\mathbf{1 2} \text { hours can be considered. NB additional quantities } \\
\text { of raltegravir will be required to cover until next review. }\end{array}$ \\
\hline \multicolumn{3}{|l|}{ H2 Blockers and Proton pump inhibitors } \\
\hline Omeprazole & $\begin{array}{l}\text { raltegravir } \mathrm{AUC} \uparrow 37 \% \\
\text { raltegravir } \mathrm{C} 12 \mathrm{hr} \uparrow 24 \% \\
\text { raltegravir } \mathrm{Cmax} \uparrow 51 \%\end{array}$ & No dose adjustment required for raltegravir \\
\hline Famotidine & $\begin{array}{l}\text { raltegravir } \mathrm{AUC} \uparrow 44 \% \\
\text { raltegravir } \mathrm{C} 12 \mathrm{hr} \uparrow 6 \% \\
\text { raltegravir } \mathrm{Cmax} \uparrow 60 \%\end{array}$ & No dose adjustment required for raltegravir \\
\hline \multicolumn{3}{|l|}{ HCV ANTIVIRALS } \\
\hline Bocepravir & $\begin{array}{l}\text { Coadministration of raltegravir ( } 400 \mathrm{mg} \text { every } 12 \\
\text { hours) and boceprevir ( } 800 \mathrm{mg} \text { three times daily) } \\
\text { increased raltegravir AUC and Cmax by } 4 \% \text { and } \\
11 \% \text {, but decreased C } 12 \mathrm{~h} \text { by } 25 \% \text {. Boceprevir AUC, } \\
\text { Cmax and C } 8 \text { h decreased by } 2 \%, 4 \% \text { and } 26 \% \\
\text { respectively }\end{array}$ & $\begin{array}{l}\text { Increased clinical and laboratory monitoring for } \mathrm{HCV} \\
\text { suppression is recommended }\end{array}$ \\
\hline Daclatasavir & $\begin{array}{l}\text { Coadministration has not been studied but based on } \\
\text { metabolism and clearance a clinically significant } \\
\text { interaction is unlikely. }\end{array}$ & $\begin{array}{l}\text { No dose adjustment of daclatasvir or raltegravir is } \\
\text { required }\end{array}$ \\
\hline Ledipasvir/Sofosbuvir & $\begin{array}{l}\text { Coadministration of raltegravir and ledipasvir } \\
\text { decreased raltegravir AUC and Cmax by } 15 \% \text { and } \\
18 \% \text {, whereas coadministration of raltegravir and }\end{array}$ & $\begin{array}{l}\text { No dose adjustment of ledipasvir/sofosbuvir or } \\
\text { raltegravir is required }\end{array}$ \\
\hline
\end{tabular}




\begin{tabular}{|c|c|c|}
\hline & $\begin{array}{l}\text { sofosbuvir decreased raltegravir AUC and Cmax by } \\
27 \% \text { and } 43 \% \text {. When raltegravir is given with } \\
\text { ledipasvir/sofosbuvir it is not known whether the } \\
\text { decrease in raltegravir will be greater. }\end{array}$ & \\
\hline Ombitasvir/paritaprevir/ritonavir & & $\begin{array}{l}\text { Raltegravir can be administered with } \\
\text { ombitasvir/paritaprevir/ritonavir and no dose alteration } \\
\text { is required. }\end{array}$ \\
\hline $\begin{array}{l}\text { Ombitasvir/paritaprevir/ritonavir + } \\
\text { dasabuvir }\end{array}$ & & $\begin{array}{l}\text { Raltegravir can be administered with } \\
\text { ombitasvir/paritaprevir/ritonavir + dasabuvir and no } \\
\text { dose alteration is required }\end{array}$ \\
\hline Simeprevir & $\begin{array}{l}\text { Coadministration of raltegravir ( } 400 \mathrm{mg} \text { twice daily } \\
\text { for } 7 \text { days) and simeprevir ( } 150 \mathrm{mg} \text { once daily for } 7 \\
\text { days) was studied in } 24 \text { subjects. Simeprevir Cmax, } \\
\text { AUC and Cmin decreased by } 7 \%, 11 \% \text { and } 14 \% \text {, } \\
\text { respectively. Raltegravir Cmax, AUC and Cmin } \\
\text { increased by } 3 \%, 8 \% \text { and } 14 \% \text {, respectively. }\end{array}$ & No dose adjustment is required. \\
\hline Sofosbuvir & $\begin{array}{l}\text { Coadministration of sofosbuvir and raltegravir ( } 400 \\
\text { mg once daily) decreased raltegravir Cmax, AUC } \\
\text { and Cmin by } 43 \%, 27 \% \text { and } 5 \% \text {, respectively. } \\
\text { Sofosbuvir Cmax and AUC decreased by } 13 \% \text { and } \\
5 \% \text {, whereas GS-331007 Cmax and AUC increased } \\
\text { by } 9 \% \text { and } 3 \% \text {. }\end{array}$ & $\begin{array}{l}\text { No dose adjustment of sofosbuvir or raltegravir is } \\
\text { required when sofosbuvir and raltegravir are used } \\
\text { concomitantly. }\end{array}$ \\
\hline Telaprevir & $\begin{array}{l}\text { Based on preliminary data, the combination of } \\
\text { telaprevir and raltegravir did not result in a clinically } \\
\text { significant interaction. }\end{array}$ & If co-administered, no dose adjustment is required. \\
\hline \multicolumn{3}{|l|}{ Miscellaneous } \\
\hline $\begin{array}{l}\text { Antidepressants (including St John's } \\
\text { Wort) }\end{array}$ & 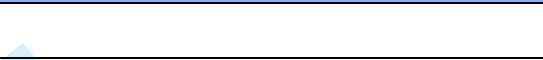 & Clinically significant interactions unlikely \\
\hline Antipsychotics/neuroleptics: & 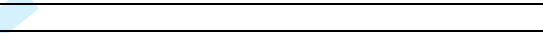 & Clinically significant interactions unlikely \\
\hline Gemfibrozil & Could potentially increase raltegravir levels & Monitor for side effects \\
\hline Methadone & & $\begin{array}{l}\text { No dose adjustment required for raltegravir or } \\
\text { methadone }\end{array}$ \\
\hline Midazolam & $\begin{array}{l}\text { midazolam AUC } \downarrow 8 \% \\
\text { midazolam } \mathrm{C}_{\max } \uparrow 3 \%\end{array}$ & $\begin{array}{l}\text { No dose adjustment required for raltegravir or } \\
\text { midazolam }\end{array}$ \\
\hline $\begin{array}{l}\text { Oral/emergency contraceptives and } \\
\text { contraceptive patch }\end{array}$ & $\begin{array}{l}\text { Ethinyl Estradiol AUC } \downarrow 2 \% \\
\text { Ethinyl Estradiol } \mathrm{C}_{\max } \uparrow 6 \% \\
\text { Norelgestromin } \mathrm{AUC} \uparrow 14 \% \\
\text { Norelgestromin } \mathrm{C}_{\max } \uparrow 29 \% \\
\end{array}$ & $\begin{array}{l}\text { No dosage adjustment required for raltegravir or } \\
\text { hormonal contraceptives (estrogen- and/or } \\
\text { progesterone-based). }\end{array}$ \\
\hline
\end{tabular}

\section{DRUG-DRUG INTERACTIONS WITH DOLUTEGRAVIR}

Since dolutegravir is an alternative agent detailed discussion of pharmacokinetics and drug-drug interactions is not included here. Like raltegravir, dolutegravir interacts with magnesium/aluminium-containing antacids - these should be taken well separated in time from the administration of dolutegravir. Other significant interactions include enzyme-inducing anti-epileptics and metformin; we advise use of The Liverpool Drug Interactions website to check interactions with all concomitant medication.

\section{DRUG-DRUG INTERACTIONS WITH PROTEASE INHIBITORS}

As these are alternatives for PEP detailed discussion of pharmacokinetics and drugdrug interactions is not included here. Ritonavir is associated with numerous drugdrug interactions and St John's Wort is contra-indicated with all PI; we advise use of The Liverpool Drug Interactions website to check interactions with all concomitant medication. 


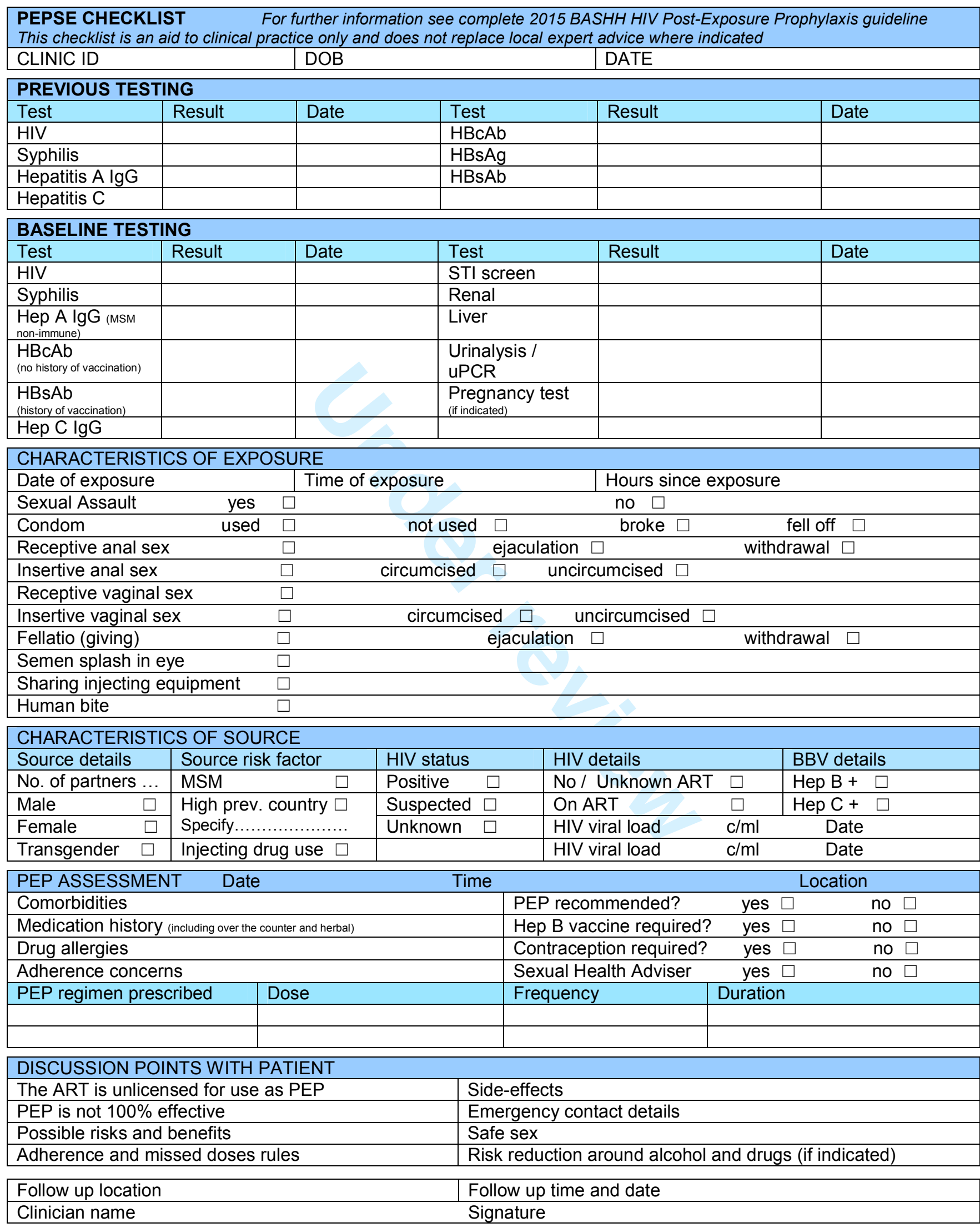




\section{APPENDIX C}

\section{LEVELS AND GRADING OF EVIDENCE}

\begin{tabular}{|c|c|}
\hline Strength of recommendation & Grading of evidence \\
\hline $\begin{array}{l}1 \text { Strong recommendation } \\
\text { For patients - most people in this } \\
\text { stuation would want the } \\
\text { recommended course of action and }\end{array}$ & $\begin{array}{l}\text { A. High quality evidence } \\
\text { Benefits clearly outweigh the risk and burdens or vice versa } \\
\text { Consistent evidence from well performed randomised controlled trials or } \\
\text { overwhelming evidence of some other form. Further research is unlikely } \\
\text { to change our confidence in the estimate of benefit or risk. }\end{array}$ \\
\hline $\begin{array}{l}\text { For clinicians - Most people should } \\
\text { receive the intervention }\end{array}$ & $\begin{array}{l}\text { B. Moderate quality evidence } \\
\text { Benefits clearly outweigh risk and burdens or vice versa } \\
\text { Evidence from randomised controlled trials with moderate limitatons } \\
\text { (inconsistent results, methodological flaws, indirect or imprecise) or very } \\
\text { strong evidence from some other research design. Further research may } \\
\text { impact on our confidence in the estimate of benefit or risk. }\end{array}$ \\
\hline $\begin{array}{l}\text { 2. Weak recommendation } \\
\text { For patients - Most people in this } \\
\text { situation would want the suggested }\end{array}$ & $\begin{array}{l}\text { C. Low-quality evidence } \\
\text { Benefits appear to outweigh the risk and burdens or vice versa } \\
\text { Evidence from observational studies, unsystematic clinical experience or } \\
\text { from RCTs with serious flaws. Any estimate of effect is uncertain. }\end{array}$ \\
\hline $\begin{array}{l}\text { not. } \\
\text { For clinicians - Examine the } \\
\text { evidence or a summary of the }\end{array}$ & $\begin{array}{l}\text { D. Very low quality evidence } \\
\text { Benefits appear to outweigh the risk and burdens or vice versa } \\
\text { Evidence limited to case studies }\end{array}$ \\
\hline $\begin{array}{l}\text { discuss that evidence with patients, } \\
\text { as well as theor values and } \\
\text { preferemces }\end{array}$ & $\begin{array}{l}\text { GPP. Good practice point } \\
\text { Recommended best practice based on the experience of the } \\
\text { guideline working group }\end{array}$ \\
\hline
\end{tabular}

